\title{
Role of Nrf2/HO-1 system in development, oxidative stress response and diseases: an evolutionarily conserved mechanism
}

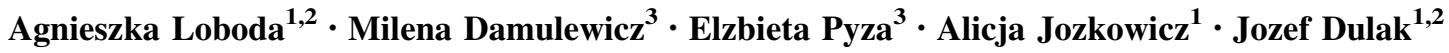

Received: 27 January 2016/Revised: 7 April 2016/Accepted: 8 April 2016/Published online: 21 April 2016

(C) The Author(s) 2016. This article is published with open access at Springerlink.com

\begin{abstract}
The multifunctional regulator nuclear factor erythroid 2-related factor (Nrf2) is considered not only as a cytoprotective factor regulating the expression of genes coding for anti-oxidant, anti-inflammatory and detoxifying proteins, but it is also a powerful modulator of species longevity. The vertebrate Nrf2 belongs to Cap ' $n$ ' Collar (Cnc) bZIP family of transcription factors and shares a high homology with SKN-1 from Caenorhabditis elegans or $\mathrm{CncC}$ found in Drosophila melanogaster. The major characteristics of $\mathrm{Nrf} 2$ are to some extent mimicked by Nrf2-dependent genes and their proteins including heme oxygenase-1 (HO-1), which besides removing toxic heme, produces biliverdin, iron ions and carbon monoxide. HO-1 and their products exert beneficial effects through the protection against oxidative injury, regulation of apoptosis, modulation of inflammation as well as contribution to angiogenesis. On the other hand, the disturbances in the proper HO-1 level are associated with the pathogenesis of some age-dependent disorders, including neurodegeneration, cancer or macular degeneration. This review summarizes our knowledge about Nrf2 and HO-1 across different phyla suggesting their conservative role as stressprotective and anti-aging factors.
\end{abstract}

Agnieszka Loboda

agnieszka.loboda@uj.edu.pl

1 Department of Medical Biotechnology, Faculty of Biochemistry, Biophysics and Biotechnology, Jagiellonian University, Gronostajowa 7, 30-387 Krakow, Poland

2 Malopolska Centre of Biotechnology, Jagiellonian University, Krakow, Poland

3 Department of Cell Biology and Imaging, Faculty of Biology and Earth Sciences, Jagiellonian University, Krakow, Poland
Keywords Heme oxygenase-1 (HO-1) ·

Kelch-like ECH-associated protein 1 (Keap1) .

Nuclear factor erythroid 2-related factor 2 (Nrf2) .

Oxidative stress - Reactive oxygen species (ROS)

\section{Adaptive response to oxidative stress through $\mathrm{Nrf2}$ and its target genes}

Living organisms are frequently exposed to oxidative stress and toxic insults, like radiation, UV light, air pollution, toxins and others. Oxidative stress generated during such stressful conditions may damage DNA and proteins, and as a consequence the cellular processes are disturbed. Special cellular machinery should be activated to fight against increased reactive oxygen species (ROS) level to protect from oxidative injury. Single cells and organisms may adapt to harmful oxidative stress conditions, through stressactivated factors.

The nuclear factor erythroid 2-related factor 2 (Nrf2; encoded by $\mathrm{Nfe} 2 l 2$ gene) is a transcription factor responsible for the regulation of cellular redox balance and protective antioxidant and phase II detoxification responses in mammals $[1,2]$. The discovery of the antioxidant response element (ARE) have led to the conclusion that the battery of genes, including glutamate-cysteine ligase (GCL), thioredoxin reductase 1 (Txnrd1), NAD(P)H-quinone oxidoreductase 1 (NQO1) and heme oxygenase-1 (HMOX1) is regulated through Nrf2 binding to this consensus binding sequence [3]. This activates cascade of events which, in the end, affects oxidative status of the cells and provides robust protection against oxidative challenge.

Nrf2 is a master eukaryotic redox-active factor and belongs to Cap ' $n$ ' Collar (Cnc)-bZIP (basic leucine zipper) family of transcription factors. Apart from Nrf2, also other 


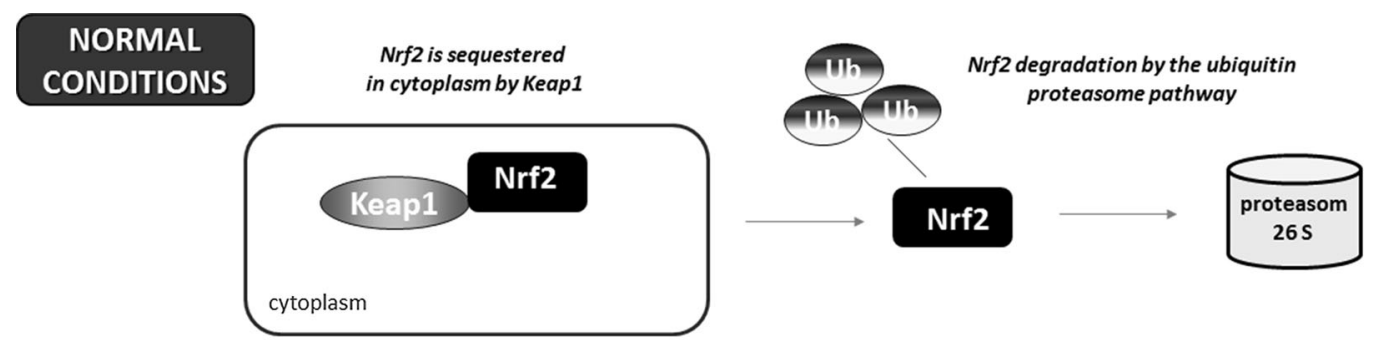

\section{STRESSFUL}
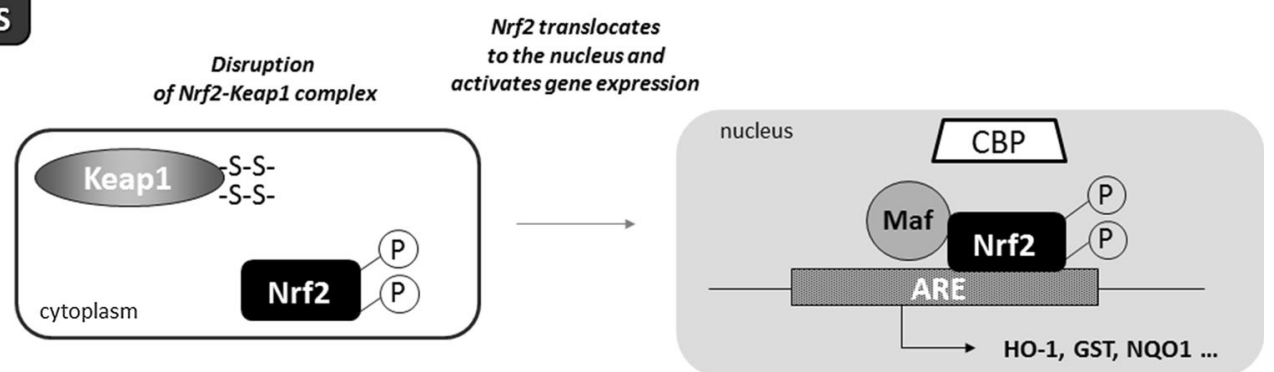

Fig. 1 Schematic representation of the Nrf2-Keap1 pathway. Under normal conditions, Nrf2 is sequestered in cytoplasm by Keap1. In stressful conditions the modification of $-\mathrm{SH}$ groups in Keap1 or phosphorylation of $\mathrm{Nrf} 2$ facilitate the dissociation of $\mathrm{Nrf} 2$ from

Keap1 as well as translocation of Nrf2 into the nucleus. After binding Maf proteins, Nrf2 activates antioxidant response element (ARE) and increases transcription of Nrf2-regulated genes (e.g., HO-1, GST, NQO-1)

NF-E2 p45-related factors 1 and 3 (Nrf1 and Nrf3) as well as transcriptional repressors Bach1 and Bach2 are the members of the family (reviewed in [4]). Nrf2 consists of six functional Neh domains (Neh1-Neh6), from which, the amino-terminal Neh2 domain controls binding Keap1-the inhibitor protein Kelch-like ECH-associated protein 1, that is responsible for the cytosolic sequestration of Nrf2 under physiological conditions (Fig. 2a). Keap1 is a cysteine-rich protein, known to be anchored to actin cytoskeleton [5], serving as an adaptor protein for the Cul3-dependent E3 ubiquitin ligase complex. Under normal conditions, Keap1 promotes ubiquitination and eventual degradation of Nrf2. This is a relatively rapid event, with Nrf2 exhibiting a short half-life of approximately $20 \mathrm{~min}$ [6]. On the other hand, under the stressful conditions, in which electrophiles and oxidants switch on Nrf2-dependent cellular defense mechanism, Nrf2 is released from Keap1 and translocates to the nucleus where it binds to conserved ARE sequence (reviewed in [7]). Keap1, as a thiol-rich protein, possesses at least 27 reactive cysteines that can be modified by electrophiles what leads to Keap1 inactivation and Nrf2 stabilization [8]. Nrf2 stabilization and increase in its halflife even to $200 \mathrm{~min}$ [9] allows nuclear translocation and activation of transcription of cytoprotective genes (Fig. 1). From abovementioned cysteines, two residues, Cys273 and Cys288, are crucial for Keap1 to control Nrf2 under both basal and stress conditions, whereas Cys151 is important for Keap1 activity predominantly in stressful conditions (reviewed in [10]).

Fig. 2 Complexity of $\mathrm{CNC}$ transcription factors and Keap1 regulator. CNC family of transcription factors share a high homology between D. melanogaster, C. elegans and Homo sapiens. From three $\mathrm{Nrf}$ factors found in vertebrates, the detailed domain structure of Nrf2 is shown. In C. elegans, three isoforms of SKN-1 factor possessing CNC domain responsible for DNA binding have been identified. In $D$. melanogaster $\mathrm{CncA}, \mathrm{CncB}$ and $\mathrm{CncC}$ have distinct $\mathrm{N}$-terminal end, but share very homologous C-terminus harboring the bZIP (a). Mammalian Keap1 consists of several domains which contain crucial cysteine residues. In zebrafish, two types of Keap1 with high homology to mammalian Keap1 are identified (similarity in amino acid sequences between zebrafish and mouse Keap1 shown in percentage). Keap1a and Keap1b, differ in the presence of essential Cys273 and Cys288, whereas dKeap1 in Drosophila lacks other cysteines but possess Cys273 and Cys288. In nematode, the function of negative regulator of SKN-1 is played by WDR-23 (b)

As mentioned above, Neh2 domain identified in Nrf2 at the N-terminal end, is responsible for Keap1 binding. This interaction requires two key amino acid sequences within Neh2: ETGE and DLG (Fig. 2a). The other functional domains in Nrf2 play an important role in the regulation of transcriptional activity or its degradation. Neh4 and Neh5 domains are capable to interact with CREB-binding protein, CBP, enhancing the transcriptional activity of Nrf2. Neh6 is rich in serine residues, and this domain together with Neh2 plays a crucial role in Nrf2 degradation. The key Neh1 domain includes CNC-bZip motif responsible for DNA binding and dimerization with small Maf proteins. The next after Neh1, is the C-terminal Neh3 domain [11-14].

Similarly, in Keap1 protein-specific domains are identified. After the N-terminal region (NTR), the BTB domain 
A

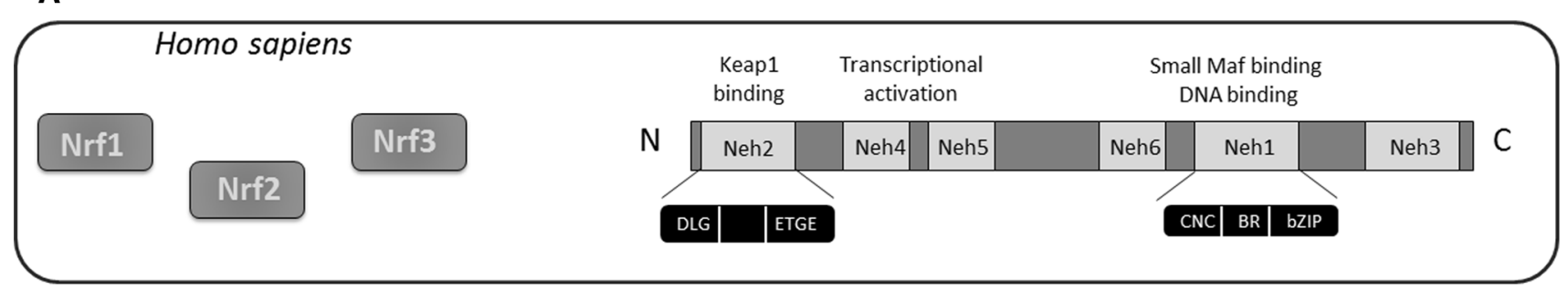

Caenorhabditis elegans

\section{SKN-1b}

SKN-1a
SKN-1c
DNA binding

$\mathrm{N}$

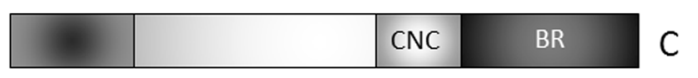

Drosophila melanogaster
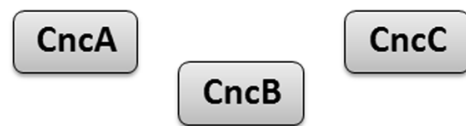

CncB -90 kDa (805 aa) N

CncA - 56 kDa (533 aa) N

bZIP

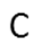

CncC- 147 kDa (1296 aa) N

D/E S/T $\quad$ HPHP VGVG AAA

\begin{tabular}{l|l|} 
CNC & bZIP \\
\hline
\end{tabular}

C

B

\section{Mammals}

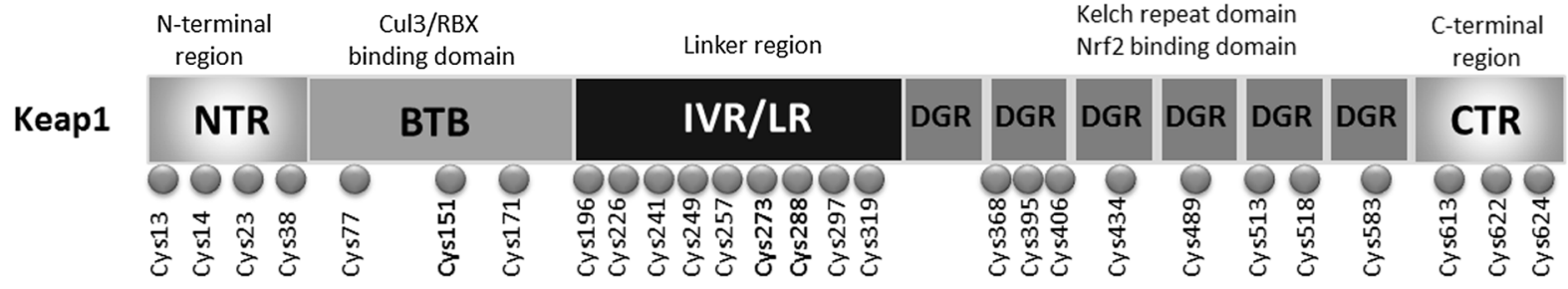

Hu et al., Chem Res Toxicol, 2011, Mitsuishi et al., Front Oncol, 2012

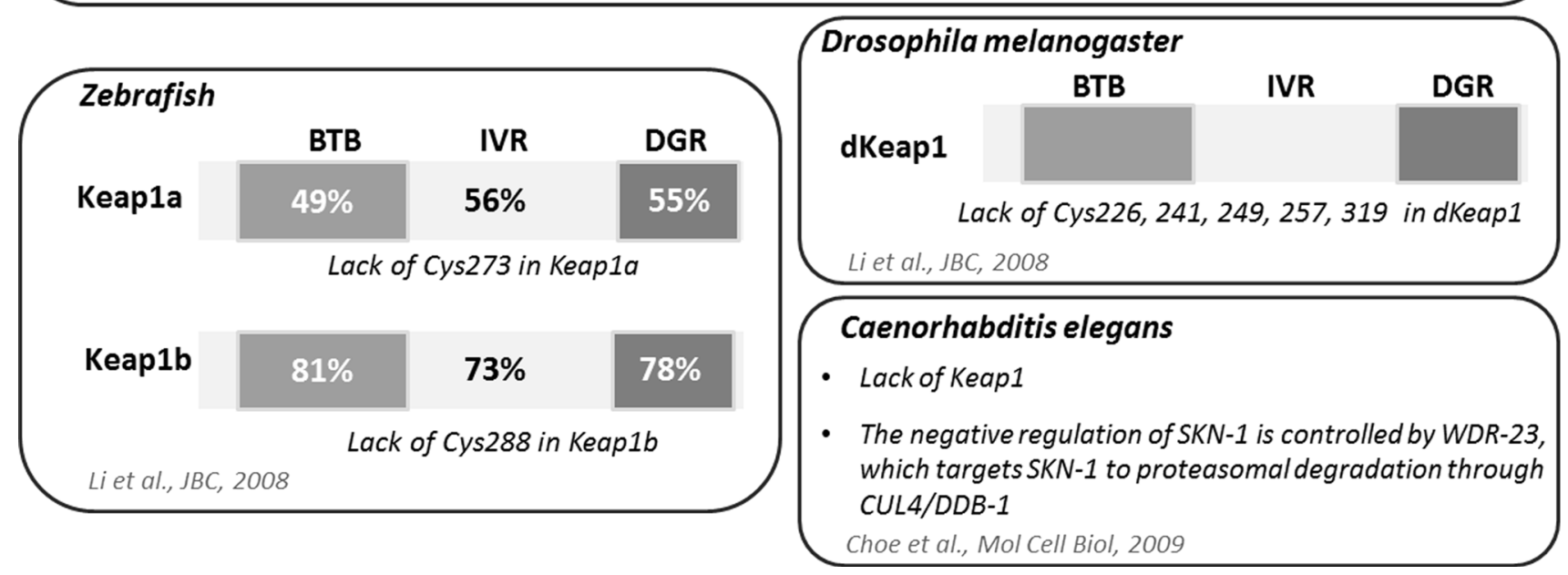


(named after the Drosophila proteins Broad complex, Tramtrack, and Bric-a-brac, in which it was first identified), required for the formation of Keap1 homodimers and recruitment of Cullin-3 (Cul3) is present. The intervening region (IVR) also contributes to interaction with $\mathrm{Cul3}$, whereas Nrf2 binding is controlled by the Kelch-repeat domain consisting of six repeats with double-glycine repeats (DGR) - key structural features of the Kelch domains (Fig. 2b) (reviewed in [10]).

\section{Evolutionary conservation of Cnc transcription factors}

Nrf2-Keap1 system has been mostly studied in mammalian cells; however, a growing body of evidence suggest that similar pathways may play an important role in the protection against oxidative stress in other organisms. In 2002, Kobayashi et al. have identified and characterized the orthologues of Nrf2 and Keap1 in the zebrafish Danio rerio as the primary regulatory system of cytoprotective enzyme genes [15]. After treatment of the zebrafish larvae with tert-butylhydroquinone (tBHQ), the induction of cytoprotective and detoxifying genes like, gstpl, nqol and $\gamma g c s h$ was observed, similarly to mammalian cells. Comparing Nrf2 of zebrafish and mouse, Kobayashi et al. found the sequence identity between the Neh1 and Neh2 domains of about $70 \%$ [15]. In 2013, Williams et al. have demonstrated that the zebrafish expresses six $n r f$ genes ( $n f e 2$, $n r f 1 a, n r f 1 b, n r f 2 a, n r f 2 b$, and $n r f 3)$. In this species, due to the whole genome duplication such multiplied copies (paralogues) that are co-orthologues of many single copy human genes are present [16]. Like the mammalian Nrf2, also in zebrafish this protein interacts with Keap1. Interestingly, two types of Keap1, Keap1a and Keap1b were identified by $\mathrm{Li}$ and coworkers [17]. It was shown that similarly to the mechanism observed in mammals, inhibition of Nrf2 by Keap1 is dependent on the interaction between Neh2 and Kelch domains as the specific mutation of the ETGE motif in Neh2 domain in zebrafish Nrf2 led to its escape from Keap1-mediated sequestration and nuclear localization [15, 17]. However, Keap1a and Keap1b lack a cysteine residue corresponding to mammalian Cys273 and Cys288, respectively [17]. Nevertheless, the presence of either Cys273 or Cys288 is sufficient for fish Keap1 molecules to exert full activity (Fig. 2b).

Similar factor to the mammalian Nrf2, responsible for oxidant signaling, was also identified in nematodes (Fig. 2). In 2003, An and Blackwell have shown that SKN1 (skinhead-1) transcription factor is an orthologue of Nrf2 [18]. They and others have found that similarly to Nrf2, under normal conditions SKN-1 is sequestered in cytoplasm, but it translocates to the nucleus in response to stressful conditions, for example after exposure to $\mathrm{H}_{2} \mathrm{O}_{2}$. In the nucleus, it binds to DNA (to the consensus WWTRTCAT ( $\mathrm{W}=\mathrm{A} / \mathrm{T}, \mathrm{R}=\mathrm{G} / \mathrm{A})$ sequence) as a monomer through a basic region (BR) [18]. Of note, $s k n-1$ gene encodes three splicing isoforms: SKN-1a, SKN-1b and SKN-1c, which share many similarities but they have also different expression patterns and functions (Fig. 2). SKN-1a plays a role in the endoplasmic reticulum stress response [19]. SKN-1b, expressed in a single pair of sensory neurons, controls lifespan in dietary restriction [20]. Finally, SKN-1c is accumulated in the intestine and it regulates expression of antioxidant and detoxification genes during stress response [18].

The negative regulation of SKN-1 is distinct from Nrf2 in mammals. A functional equivalent of mammalian Keap1, XREP-1 (WDR-23), was identified to control SKN1 activity [21]. This regulation is based on the recruitment of SKN-1 to the CUL4/DDB1 (cullin 4/damaged DNA binding protein 1) ubiquitin ligase in nucleus leading to proteasomal degradation of this transcription factor and stopping its activity [22].

Additionally, in Drosophila melanogaster cnc gene was identified and named based on its striking expression pattern in the anterior most labral segment (cap) and the mandibular segment (collar) of embryos [23]. The $c n c$ gene encodes a bZIP transcription factor [23] and shares $60 \%$ similarity over 160 aa with the p45 subunit of the NF-E2 transcription factor [24]. This homology includes $95 \%$ identity in the 20 amino acid DNA-binding domain. Moreover, the DNA-binding domain of $c n c$ is also shared with skn-1 [23].

Due to alternative splicing $\mathrm{Cnc}$ has three isoforms: $\mathrm{CncA}, \mathrm{CncB}$ and $\mathrm{CncC}$ which have distinct N-terminal end, but share very homologous $\mathrm{C}$-terminus harboring the bZIP. Additional coding variants (longer isoforms) were identified and reported in Flybase [25], but their functions are not fully characterized. $\mathrm{CncA}$ and $\mathrm{CncB}$ are presumably maternal and they are detectable at syncytial and early cellular blastoderm stages, then they disappear until stage 14 [26]. CncA and $\mathrm{CncC}$ are required for germ cell viability and early oogenesis [27]. The $c n c B$ is expressed in an embryonic pattern that includes the labral, intercalary and mandibular segments. $\mathrm{CncB}$ protein is 272 amino acids longer than CncA isoform and it this part His-Pro, Ala, Val-Gly and Pro repeats are present (Fig. 2). This difference on the N-terminus is essential for repressive effect on Deformed (Dfd) response elements. CncC protein also possesses this 272 amino acid domain, and it has additional 491 amino acids, enriched in Ser-Thr and Asp-Glu motifs, at its $\mathrm{N}$ terminus that are unique to this isoform.

The molecular mechanism of stress response in insects is similar to that described in mammals. In unstressed conditions, $\mathrm{CncC}$ is retained in the cytoplasm by the actin- 
associated protein Keap1 [28]. Additionally, CncC activity is limited by dKeap1, which serves as an adaptor protein for Cul3-based ubiquitin ligase, targeting $\mathrm{CncC}$ for degradation [29]. The comparison of amino acid sequence homology between human Keap1 protein and Drosophila dKeap1 is presented in the recent review by Pitoniak and Bohmann showing conservation in BTB domain, linker domain and also in Kelch-repeat domain (see review [25]). $\mathrm{Li}$ and coworkers [17] have found that dKeap1 lacks Cys226, Cys241, Cys249, Cys257, Cys 319 but possess the crucial Cys273 and Cys288, enabling dKeap1 to be fully active.

In normal conditions, AREs are blocked by small Maf (Maf-S) (musculo aponeurotic fibrosarcoma) protein [30, 31]. Maf-S does not have transcription activation domain, and after its binding to ARE, target gene expression is not activated. After stress exposure, electrophiles and ROS disrupt interaction between $\mathrm{CncC}$ and Keap1. CncC is not degraded and it is accumulated in the nucleus, where it forms heterodimers with Maf-S, binds to AREs and activates target genes transcription [32]. This mechanism is necessary for transcriptional responses to many xenobiotics, like chlorpromazine, caffeine or the pesticide malathion [29] and represents evolutionarily conserved mechanism of cell adaptations to stressful conditions.

In Drosophila, in contrast to mammals, where Nrf2 affects only phase II genes, $\mathrm{CncC}$ regulates the expression of genes involved in every phase of detoxification. It is important to remind that detoxification process may be divided into three phases. Phase I is realized by many enzymes, like cytochrome P450 monooxygenases, which decrease biological activity of xenobiotics. Phase II is a process of conjugation, when metabolites produced in the phase I are linked with carboxyl-, hydroxyl-, amino-, or sulfhydryl-groups. In this phase glutathione $S$-transferases (GSTs) or UDP-glucuronosyltransferases (UGTs) play the crucial role in the increase of hydrophilicity of xenobiotics and carboxylesterases. Phase III is a final modification and excretion, dependent on ATP-binding cassette (ABC) and other transmembrane transporters. Misra et al. have found that $\mathrm{CncC}$ causes changes in the expression of enzymes involved in all phases of detoxification, including 36 different P450, 17 GSTs, six UGTs and 55 different transporters [33]. It is worth to highlight that three P450 genes-Cyp6g1, Cyp6g2 and Cyp12d1-which are upregulated by $\mathrm{CncC}$, are responsible for pesticide resistance in insects $[34,35]$. It was also shown that $\mathrm{CncC} / \mathrm{Keap} 1$ pathway is constitutively active in insecticide-resistant Drosophila strains [32]. An additional protection against xenobiotics is CncC-dependent up-regulation of cuticle gene expression [33]. $\mathrm{CncC}$ also regulates many metabolic pathways which may be connected with detoxification. For example, $\mathrm{CncC}$ up-regulates $Z w$ and $P g d$, encoding glucose-6-phosphate dehydrogenase and phosphogluconate dehydrogenase, respectively. These enzymes are involved in pentose phosphate pathway and they are critical for NADPH production, which is essential for P450 and GST function [33]. Interestingly, Jones et al. showed that additional response to xenobiotics is provided by intestinal Lactobacilli, causing ROS-dependent activation of $\mathrm{Cnc}$ pathway [36].

In $C$. elegans oxidative stress causes accumulation of SKN-1 in intestinal nuclei and activation of gene expression from I, II and III detoxification phase. Moreover, $\mathrm{SKN}-1$ induces the expression of C-type lectins, which are localized on the intestinal surface and are known as antimicrobial agents [37]. In addition, it has been suggested that SKN-1 maintains lipid homeostasis and it may be important for longevity [37]. This factor up-regulates lipid metabolism genes in starvation or dietary conditions, which induces fat mobilization. SKN-1 responds to elevated lipid levels by activation of gene transcription involved in $\beta$ oxidation, lipolysis, fatty acid desaturation, elongation, and transport [38].

In summary, $\mathrm{CncC}$ in Drosophila, $\mathrm{SKN}-1$ in nematodes as well as vertebrate Nrf2 represent the same family of conserved factors having the unique 43-amino acid CNC domain located N-terminally to the DNA-binding domain (Fig. 2). These factors modulate the stress response in several scenarios, and therefore we discuss their potential role in both the normal and pathologic conditions.

\section{Role of Cnc transcription factors in development}

Transcription factors belonging to the CNC-bZIP family play a crucial role in an organism growth. SKN-1 is critical for development of the endoderm and mesoderm, especially it initiates the formation of the digestive system and other mesendodermal tissues in C. elegans. Interestingly, SKN-1 is asymmetrically distributed within the embryo (Fig. 3). In two-cell embryo skn-1 mRNA is deposited in both cells [39], but protein is expressed at higher level in the posterior cell. This asymmetry is regulated by EEL-1, that is the Hect E3 ubiquitin ligase, targeting SKN-1 for degradation [40]. In four-cell embryo these differences in SKN-1 concentration are even more pronounced with high level of SKN-1 in the posterior daughter cells. SKN-1 determines the mesendodermal EMS precursor cell [41, 42]. EMS divides into the mesodermal MS precursor that develops into pharynx and muscles, and the $\mathrm{E}$ precursor which generates all 20 intestine cells. SKN-1 directly induces the expression of the transcription factors med-1 and med-2, which activate expression of the GATA factors end- 1 and end-3 in the E cell $[43,44]$. In contrast, in the MS precursor maternally deposited POP-1 inhibits END-1, 


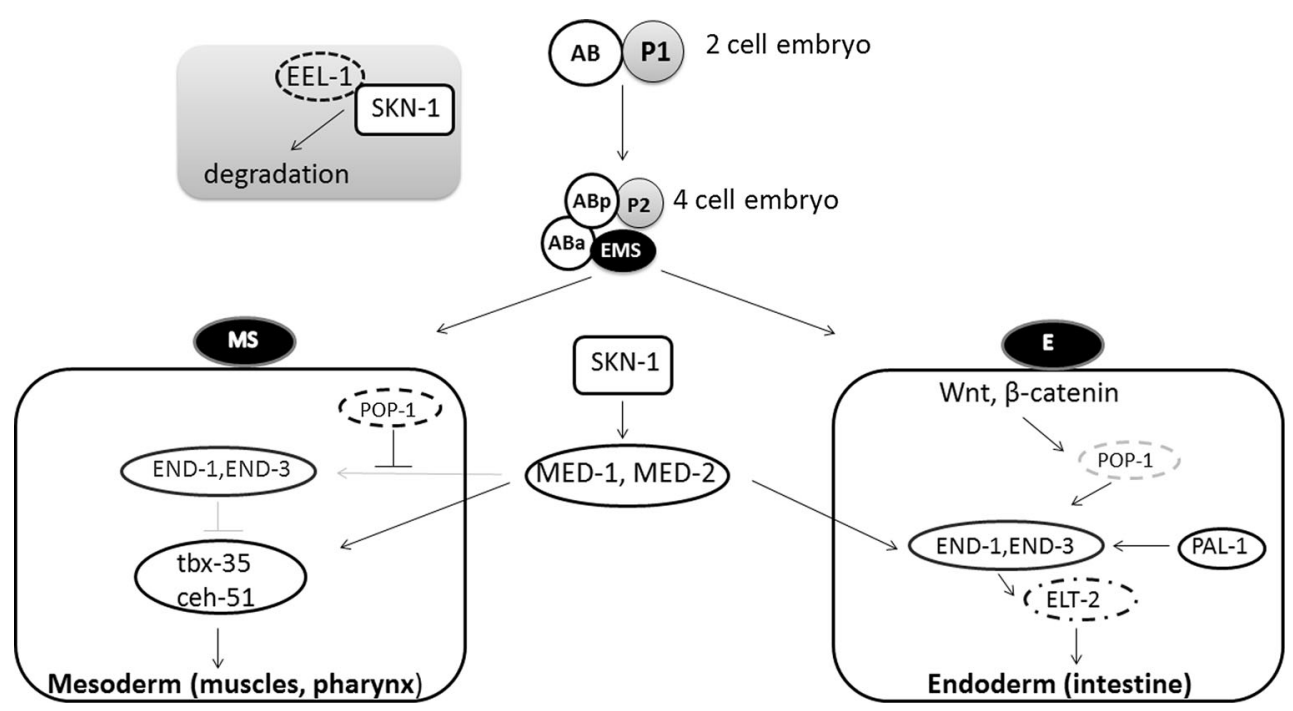

Fig. 3 The role of SKN-1 in the development of C. elegans. In the early embryo skn-1 mRNA is deposited in both cells: AB and P1, but the level of SKN-1 protein is higher in the posterior cell (P1). This asymmetry is regulated by EEL-1, which binds SKN-1 and targets it to degradation mainly in $\mathrm{AB}$ cell. After division $\mathrm{AB}$ cell forms Aba (anterior) and $\mathrm{ABp}$ (posterior) cells and P1 forms P2 and EMS cells. In this four-cell embryo, SKN-1 is concentrated mostly in EMS cell. In the next step, EMS divides into the mesodermal MS precursor, which develop into pharynx and muscles, and the endodermal $\mathrm{E}$

3 , and this results in blocking intestine development pathway. Moreover, in MS cells MED-1,2 activate T-box transcription factor tbx-35, that stimulates ceh-51, and then together they initiate a pathway for mesodermal specification [45, 46]. In the E precursor, POP-1 is modified through Wnt-dependent pathway, and this decreases its nuclear level and cooperation with $\beta$-catenin SYS- 1 to activate END-1,3 [47, 48]. END-1,3 cooperate each other to activate elt-2, a crucial gene in intestine development [49-51]. After the eight-cell stage, EEL-1 downregulates $\mathrm{SKN}-1$ and this protein is no longer detected in the early embryo $[18,40]$.

The role of CNC factors is Drosophila development is also well described. Cnc function starts during oogenesis, when particular maternal mRNAs are deposited in oocytes. These mRNAs are localized in a specific place of oocyte and after fertilization they are translated for proteins, which are necessary to form the anterio-posterior axis of embryo. Maternally deposited Cnc (A or C isoform) is required for proper microtubules positioning and affects anchoring of the nucleus to the anterior cortex of the oocyte [52].

$c n c B$ transcription is activated in blastoderm and continuous during embryogenesis in two parts of embryo: the anterior part called "cap" expression domain and in the mandibular segment that corresponds to the "collar" domain $[23,53]$. The specific $c n c$ expression pattern results from function of many genes, including knot $(\mathrm{kn})$ [known precursor, which generates intestine cells. SKN-1 increases level of the transcription factors MED-1 and MED-2, which in turn activates end-1,3 transcription. In MS cell POP-1 protein inhibits END-1,3, whereas MED-1 and MED-2 activate transcription factors: tbx-35 and ceh-51, which are crucial for mesoderm development. In E cell POP-1 is modified on $\mathrm{Wnt} / \beta$-catenin-dependent pathway, what activates END-1,3. END-1,3 cooperate with each other to increase the level of ELT-2, which starts intestine development

also as collier $(\mathrm{col})]$ [54, 55], bicoid, torso, tailless (tll), snail (sna), spalt (sal) and giant (gt) [56]. CncB controls development of cephalic segments: the anterior compartment of the mandibular segment and the labral segment [23]. In mandibular development $\mathrm{CncB}$ cooperates with homeotic Deformed $(D f d)$ gene. Tissues expressing $\mathrm{CncB}$, but not Dfd, form hypopharynx. In mandibular cells and in some maxillary cells, CncB inhibits Dfd-activated gene transcription. Of note, tissues expressing both $\mathrm{CncB}$ and Dfd develop mandibular lobe-derived structures. Finally, tissues expressing Dfd only, (but not $\mathrm{CncB}$ ) drive maxillary development [57]. Although the $\mathrm{N}$-terminal of $\mathrm{Cnc}$ acts as a strong transcriptional domain, $\mathrm{CncB}$ function requires Maf-S protein, a homolog of the mammalian small Maf. Maf-S can potentially form heterodimers with all $\mathrm{Cnc}$ isoforms but, in contrast to the mammalian Maf protein, it is not able to form homodimers and to bind to DNA itself. $\mathrm{CncB} / \mathrm{Maf}-\mathrm{S}$ heterodimers bind a specific sequence (TGCTGAGTCAT) that is very similar to the mammalian Nrf/Maf binding site [31]. Other isoforms, CncA and $\mathrm{CncC}$, also affect embryogenesis, but their specific functions are not well described yet [26].

$\mathrm{CncB}$ is also crucial for development of the pharynx and it is a pharynx selector gene. In the labral and dorsal pharyngeal region Cnc maintains the specific pattern of segment polarity gene expression, hedgehog $(h h)$ and wingless (wg) [31, 58]. Both proteins Hedgehog and 
Fig. 4 Cnc factors regulate development of $D$. melanogaster. Maternally deposited Cnc has important functions in egg polarization. In embryo Cnc is concentrated in the anterior part, in "cap" and "collar" domains. Cnc cooperates with Dfd in tissue development. In cells which express both Cnc and Dfd, Cnc forms heterodimers with MafS protein, and inhibits Dfd function. As the result, mandibular structures develop. Cells expressing only Dfd develop into maxillary structures. Finally, cell expressing Cnc only form pharynx structures

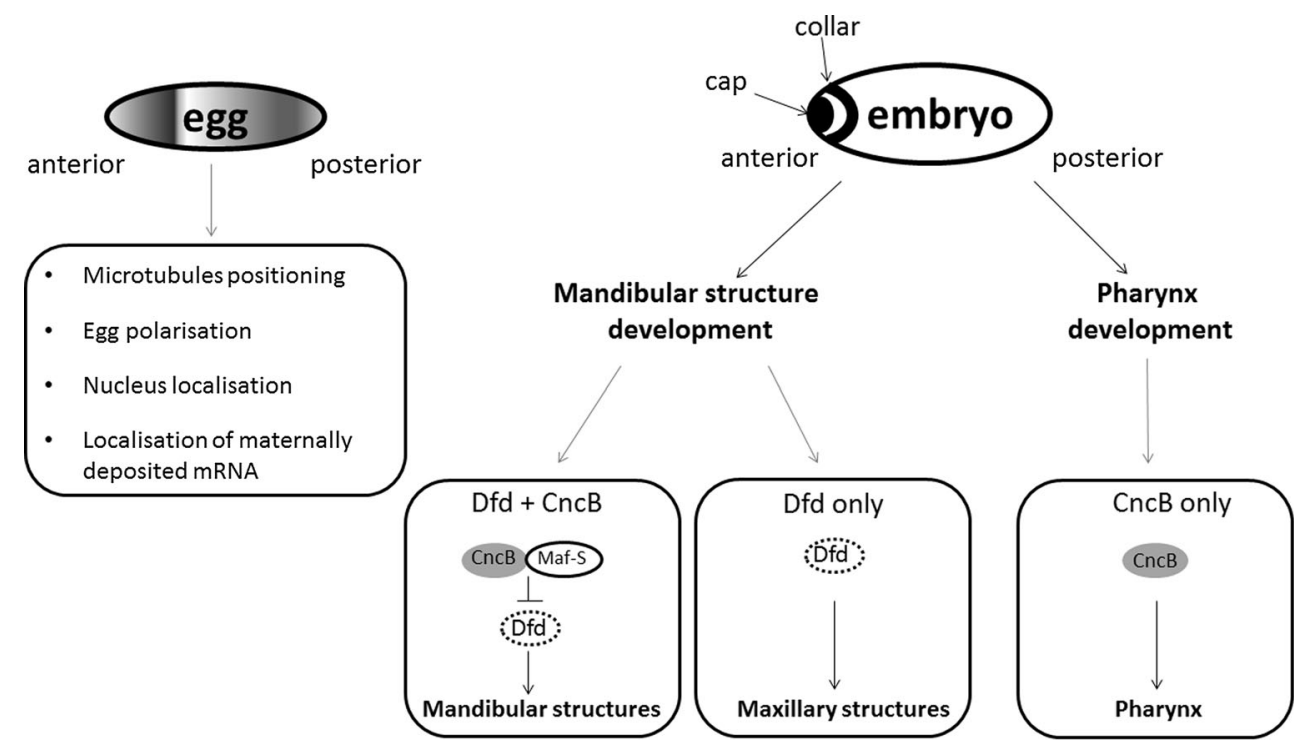

Wingless are necessary to the pharynx development. The involvement of Cnc transcription factors in Drosophila development is schematically summarized in Fig. 4.

In Drosophila, CncC controls also metamorphosis through the regulation of ecdysone biosynthetic genes and ecdysone response genes. In this pathway, $\mathrm{CncC}$ requires Drosophila Keap1 (dKeap1) as a partner. Both, CncC and dKeap1 are localized predominantly in the nucleus. dKeap1 interacts with $\mathrm{CncC}$ and then binds to specific loci (ecdysone-regulated early puffs) on the polytene chromosomes and maintains open chromatin structure that facilitates transcription. The reduction of $\mathrm{CncC}$ or dKeap1 in the prothoracic gland, the organ producing ecdysone, leads to the reduction of ecdysone biosynthetic gene transcription, decrease in ecdysone level and delayed pupation. CncC may also interact with Ras signaling pathway in metamorphosis and transcriptional regulation. Phosphorylation of $\mathrm{CncC}$ in response to Ras and possibly other signals can regulate the distribution of $\mathrm{CncC}$ on chromatin, resulting in the regulation of development and metamorphosis [59, 60].

In Drosophila, Cnc is involved in the regulation of intestinal stem cells (ISC) maintenance. ISC are the only cells in the intestinal epithelium which proliferate and are responsible for regeneration of the midgut. This process needs to be precisely regulated because an excessive proliferation in the intestine can result in disruption of the intestinal epithelium by the accumulation of misdifferentiated ISC daughter cells, as it has been observed in stress conditions and aging. Hochmuth et al. showed that $\mathrm{CncC}$ Keap1 regulate ISC proliferation rates by influencing the intracellular redox state. $\mathrm{CncC}$ is constitutively active in ISC of young, unstressed flies and maintain low ROS level leading to inhibition of ISC proliferation. In older flies, in oxidative stress conditions, $\mathrm{CncC}$ activity is repressed by Keap1, and increases proliferation rate [61].

In vertebrates, the regulation of the embryonic development by Nrf transcription factors was examined in several studies. It has been shown that deletion of Nrf1 in mice leads to anemia, defects in erythropoiesis and death [62]. In contrast to Nrf1, the inactivation of the $N f e 2 l 2$ gene did not induce obvious defects in knockout mice, indicating that Nrf2 is dispensable for growth and development [63]. Similarly, also Nrf3 knockout mice survive healthy [64]. Leung et al. [65] have observed that deficiency of both Nrf1 and Nrf2 results in early embryonic lethality of mice and this indicates a compensatory effect of Nrf1 in case of $N f e 2 l 2$ knockout. Increased apoptosis has been observed in embryos lacking both transcription factors and fibroblasts isolated from $\mathrm{Nrf}^{-/-} \mathrm{Nrf} 2^{-I-}$ mice exhibit increased intracellular ROS levels and enhanced sensitivity to oxidative stress.

\section{Heme oxygenase-1 as an Nrf2-dependent gene}

The Keap1-Nrf2 pathway regulates the expression of numerous cytoprotective genes (Table 1) including antioxidant ones, genes encoding enzymes that participate in the synthesis and regeneration of glutathione, detoxifying molecules, proteins that regulate the expression of other transcription factors and growth factors and many more.

One of the genes regulated through Nrf2 is heme oxygenase-1 (HO-1, HMOX1, EC 1.14.99.3) [66]. HO-1 is one of two distinct $\mathrm{HO}$ isoforms found in mammals. It serves as an inducible $32-\mathrm{kDa}$ protein, highly upregulated by a number of stimuli like heme, nitric oxide, heavy metals, growth factor, cytokines, modified lipids and others. In 
Table 1 Cytoprotective genes regulated by Nrf2 transcription factor

\begin{tabular}{|c|c|c|}
\hline Gene & Abbreviation & Major function \\
\hline Ferritin & Fn & Sequesters free iron \\
\hline $\begin{array}{l}\text { Glucose-6-phosphate } \\
\text { dehydrogenase }\end{array}$ & G6PD & Provides NADPH to gluthathione reductase \\
\hline Gluthahione peroxidase & GPx & Detoxifies peroxides and hydroperoxides \\
\hline Gluthathione $S$-tranferases & GSTs & Catalyze the conjugation of the reduced form of glutathione (GSH) to xenobiotic substrates \\
\hline Gluthathione reductase & GR & $\begin{array}{l}\text { Catalyzes the reduction of glutathione disulfide (GSSG) to the sulfhydryl form of glutathione } \\
\text { (GSH) }\end{array}$ \\
\hline$\gamma$-Glutamylcysteine ligase & GCL & Catalyzes the rate limiting step in the cellular glutathione (GSH) biosynthesis pathway \\
\hline Heme oxygenase-1 & HO-1 & Degrades heme and generates the antioxidant molecules, biliverdin and $\mathrm{CO}$ \\
\hline $\begin{array}{l}\text { NAD }(\mathrm{P}) \mathrm{H}: \text { quinone } \\
\text { dehydrogenase } 1\end{array}$ & NQO1 & FAD-binding protein, reduces quinones to hydroquinones \\
\hline Sulfotransferases & SULFs & Catalyze sulfation of many xenobiotics \\
\hline Superoxide dismutase & SOD & $\begin{array}{l}\text { Catalyzes the dismutation of the superoxide radical }\left(\mathrm{O}_{2}{ }^{-}\right) \text {into molecular oxygen }\left(\mathrm{O}_{2}\right) \text { or } \\
\text { hydrogen peroxide }\left(\mathrm{H}_{2} \mathrm{O}_{2}\right)\end{array}$ \\
\hline Thioredoxin reductase & TR & Reduces thioredoxin \\
\hline UDP-glucose dehydrogenase & UGDH & Converts UDP-glucose to UDP-glucuronate \\
\hline
\end{tabular}

Fig. 5 Heme oxygenase-1 pathway. HO-1, and inducible enzyme, cooperating with NADPH cytochrome P450 degrades heme to produce three bioactive products: iron ions, carbon monoxide and biliverdin, which is rapidly converted to bilirubin, through the action of biliverdin reductase (BVR). Tissue protection is exerted by the activity of all products and their functioning as a proangiogenic, antioxidant or antiinflammatory factors

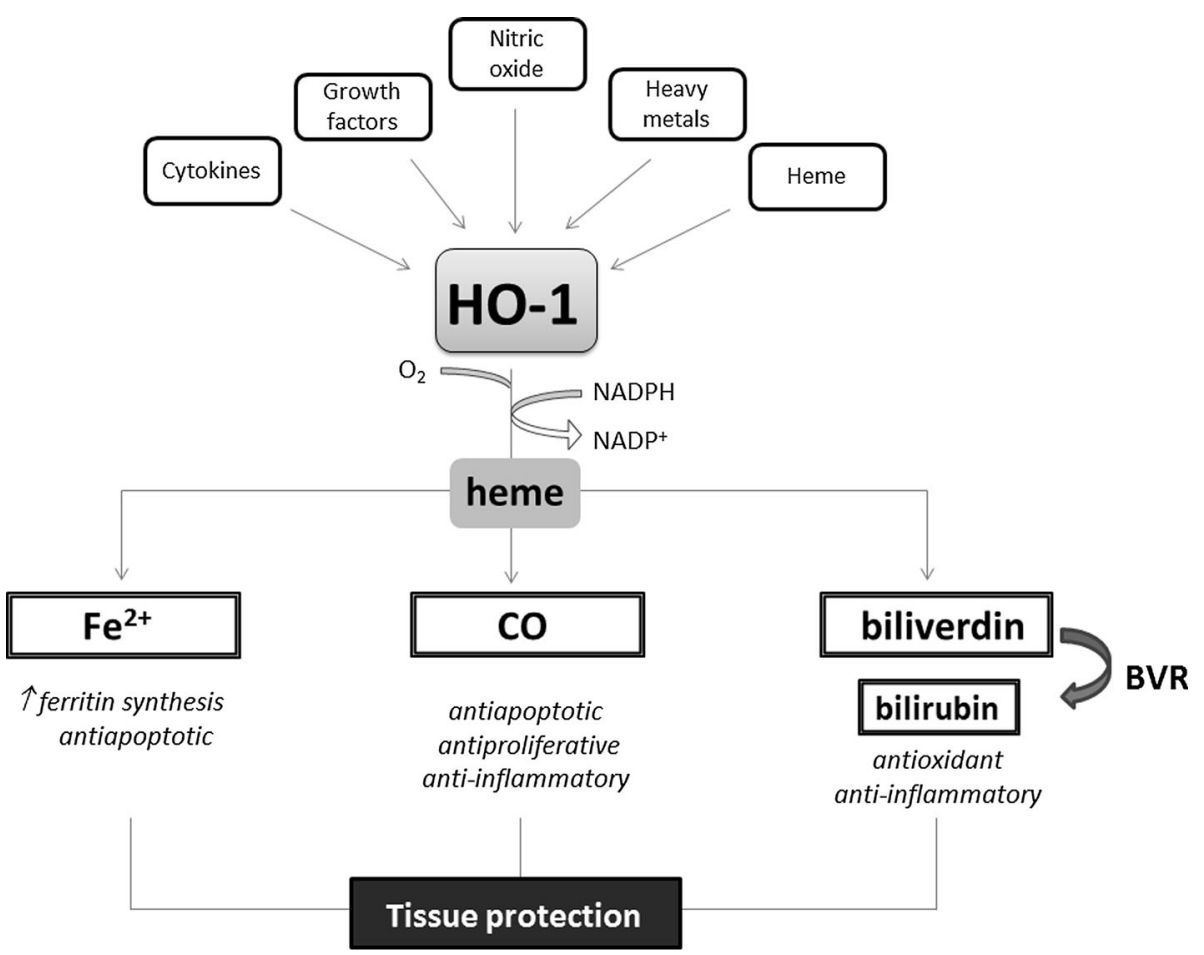

contrast, HO-2 isoform is expressed constitutively (reviewed in [67]).

This cytoprotective enzyme catalyzes the rate-limiting step in heme degradation, leading to the generation of equimolar amounts of iron ions, biliverdin and CO (Fig. 5). Biliverdin together with bilirubin, formed thanks to the action of biliverdin reductase (BVR), are potent antioxidants, but also the other products of HO-1 activity regulate important biological processes including inflammation, apoptosis, cell proliferation, fibrosis, and angiogenesis. Iron is known to facilitate the generation of reactive oxygen species through Fenton reaction and might be possible toxic product of enzyme activity; however, already in 1992, Balla et al. [68] have shown that induction of HO-1 in endothelial cells exposed to $\mathrm{H}_{2} \mathrm{O}_{2}$-induced oxidative stress is accompanied with induction of ferritin, a protective enzyme sequestering iron ions. Such association between HO-1 and ferritin has been demonstrated also 
in vivo, e.g., in the inflammatory glomeruli in human lupus nephritis [69]. Both enzymes were expressed with similar pattern in the glomeruli and what is more, the transcript of ferritin heavy chain was decreased when HO-1 was knocked down. On the other hand, the stimulation of HO-1 was able to exert only partial protective effect against oxidative stress in cells lacking ferritin heavy chain, indicating cooperation of both enzymes [69]. It seems that CO is a major product of HO-1 activity playing a protective role both in physiology and in pathological conditions (for review see $[70,71])$.

The importance of HO-1 has been underlined by the studies on HO-1 knockout animals. Poss and Tonegawa [72, 73] as well as Yet et al. [74] have created different strains of HO-1-null mice. In 1999, Yachie et al., reported the first known human case of HO-1 deficiency in 6-yearold boy with severe growth retardation [75]. Another case of human HO-1 deficiency was described 12 years later by Radhakrishnan et al. [76]. The results from those human cases of HO-1 deficiency generally confirmed animal studies. The major symptoms observed in HO-1-deficiency included enhanced systemic inflammation, abnormalities of the coagulation/fibrinolysis system, developmental failure, iron-deficiency anemia, intravascular hemolysis with fragmented erythrocytes, nephropathy, and vascular endothelial injury [75]. Almost the only one difference observed in human and mice deficiency was the asplenia in human case, whereas splenomegaly was noticed in the young knockout mice. Thus, one can sum up that the inadequate HO-1 level may result in a broad spectrum of severe side effects, which could affect many organs (reviewed in [67]). This may also explain why only two cases of human HO-1 deficiency have been described till now.

On the other hand, basal and induced expression of HO1 can vary in the human population because of the highly polymorphic $(\mathrm{GT})_{n}$ fragment in the promoter, which may significantly modulate cytoprotective, anti-inflammatory and pro-angiogenic functions of HO-1 [77]. The distribution of alleles with different $(\mathrm{GT})_{n}$ lengths is bimodal within the human population, with the most frequent variants in Caucasians containing 23 and 30 repeats. The results from many studies have clearly shown that longer $(\mathrm{GT})_{n}$ sequences are associated with diminished HO-1 expression and lower resistance to oxidative stress. Short $(<25$ GT) repeats are associated with higher HO-1 basal expression and stronger up-regulation after stimulation than longer repeats. The association between HO-1 polymorphism and occurrence/progression of some diseases, mostly cardiovascular disease risk has been suggested (reviewed in [67]). The recent study by Pechlaner et al. [78] confirmed previously reported relations and showed that subjects with $\geq 32$ tandem repeats on both $\mathrm{HO}-1$ alleles display substantially increased cardiovascular disease risk and enhanced atherosclerosis progression. However, human genome epidemiology (HuGE) meta-analysis of HO-1 polymorphism and susceptibility to coronary artery disease (CAD) from 11 studies, involving 10,170 patients with CAD and 6868 controls, performed in 2014 by Qiao et al. [79] revealed no significantly decreased risk of CAD in patients with the SS genotype of the HO- $1(\mathrm{GT})_{n}$ repeat length polymorphism compared with those with the $\mathrm{LL}+\mathrm{SL}$ genotype. However, the results from the subgroup analyses showed that the (GT) $)_{n}$ SS genotype or S allele were associated with decreased CAD risks in Asian population and in studies with age- and sex-matched subgroups. Qiao et al. underlined that the lack of association between HO-1 polymorphism and CAD in Caucasian population found in their analysis may be at least partially caused by some limitations of the studies performed, and stressed the need of proper age and sex matching [79].

Besides cardiovascular disorders, the presence of long $(\mathrm{GT})_{n}$ repeats has been suggested to be a prognostic marker for several cancer, but overall the results are complex. In oral squamous cell carcinoma [80], gastric adenocarcinoma [81] and lung adenocarcinoma [82] the lack of short allele corresponds with a higher incidence of cancer. On the other hand, in pancreatic cancer patients, an increasing risk was evident between LL, SL, and SS genotype, with the latter genotype displaying the most aggressive tumor biology [83]. Also in melanoma patients the homozygous short allele with $<25(\mathrm{GT})_{n}$ repeats $(\mathrm{S} / \mathrm{S})$ has been found more frequently in the melanoma group compared to the healthy control population and this genotype characterized tumors with deeper Breslow thickness compared to L-allele carriers [84]. However, similarly to cardiovascular disorders, the recent meta-analysis has shown lack of the association between HO-1 (GT) ${ }_{n}$ repeat polymorphism and cancer susceptibility. Zhang et al. [85] analyzed 10 studies involving 2367 cases and 2870 controls and found that overall cancer risk was not ascribed to the length of $(\mathrm{GT})_{n}$ sequence; however, some sub-group analysis revealed higher risk of squamous cell carcinoma in persons carrying longer $(\mathrm{GT})_{n}$ repeats in the HO-1 gene promoter. Nevertheless, in recent study, $\mathrm{Wu}$ et al. have found that participants with the SS genotype had an increased risk of lung squamous cell carcinoma versus those with L/S or L/L genotype. Moreover, in S/S genotype, higher incidence of Bowen's disease and invasive skin cancer has been observed, while the participants with the S-allele had a reduced risk of lung adenocarcinoma versus those with L/L genotype [86].

Interestingly, the length of $(\mathrm{GT})_{n}$ repeats in the HO-1 promoter did not influence the onset of neurodegenerative diseases such as Alzheimer's disease (AD) and Parkinson's disease (PD) [87, 88]. However, Infante et al. have shown that a $-413 \mathrm{~A} / \mathrm{T}$ single-nucleotide polymorphism (SNP) in HO- 1 , together with glycogen synthase kinase-3 $\beta$ (GSK3 $\beta$ ) 
(-157, rs6438552) TT genotype had four times higher risk of developing PD than subjects without these genotypes [89].

\section{Role of HO-1 in embryogenesis and pregnancy}

It is well established that HO-1-deficiency results in embryonic death and some studies evaluated the role of HO-1 in embryonic survival. HO-1 is expressed in the placenta and in the pregnant uterus already on embryonic day 6.5 (E6.5) [90]. Placenta of E14.5 embryos expresses very high levels of HO-1 mRNA, protein and activity [90]. Similarly, rat placenta expresses high HO-1 at day 15 of pregnancy [91]. Also in humans HO-1 is expressed in trophoblast and is highly induced during pregnancy, being a factor supporting pregnancy and decreasing abortions. Moreover, reduced HO-1 level was shown to be associated with miscarriages and pregnancy complication including pre-eclampsia (reviewed in [92]). Interestingly, the mother of the Japanese HO-1-deficient patient, was found to be heterozygous for Hmoxl and she had experienced two intrauterine fetal deaths [75]. Also experiments on mice lacking both or one HO-1 allele support the crucial role of HO-1 in placenta and in pregnancy. Zhao et al. observed that HO-1 deficiency resulted in fetal lethality and decreased litter sizes [93] and also our own group have noticed abnormally low birth rate of $\mathrm{HO}-1^{-/}$offspring, born from $\mathrm{HO}-1^{+/-}$parents (unpublished data). Intrauterine abortions of $\mathrm{HO}-1^{-/-}$embryos, observed regularly in HO$1^{+/-}$cross-breedings, were reported to occur before E10.5 [93]. Additionally, the weight of placenta in $\mathrm{HO}-1^{+/-}$mice was reduced due to the apoptosis in the spongiotrophoblast layer. On the other hand, HO-1 overexpression was shown to improve pregnancy outcome in mice [94]. The detailed mechanisms responsible for $\mathrm{HO}-1$ contribution to ovulation and fertilization, implantation and placentation is elegantly summarized in the recent review by Zenclussen [92]. In vivo experiments in rats showed the regulation of insulinlike growth factor (IGF) binding protein-1 by placental or trophoblastic HO-1 [95]. Noteworthy, IGF was reported to enhance the blastocyst formation, increase the number of blastomeres in cultured murine embryos, and to facilitate the establishment of stem cell lines [96]. HO-1 may also directly affect differentiation of pluripotent stem cells. Lin et al. generated induced pluripotent stem cells (iPSc) from embryonic fibroblasts, isolated from $\mathrm{HO}-1^{+/+}, \mathrm{HO}-1^{+/-}$, and $\mathrm{HO}-1^{-1-}$ mice, using Oct3/4, Sox2, Klf4 and c-Myc reprogramming factors [97]. After prolonged cell culture, the reduced expression of pluripotency markers in $\mathrm{HO}-1^{-1-}$ cells, increased sensitivity to oxidant-induced cell death and augmented differentiation were detected [97].

\section{Heme oxygenase system in prokaryotic and eukaryotic species}

As it was described above, Nrf2 transcription factor shares high homology with their counterparts in Drosophila, nematodes or zebrafish, but importantly, they are not present in plants and fungi. In contrast, there is a high degree of evolutionary conservation of the heme-degrading enzymes among animal, plant, and fungal kingdoms. In vertebrates, the structural similarity and functional identity between $\mathrm{HO}$ enzymes is reported. Moreover, in bacteria, fungi, plants and flies, HO-1-like proteins or analogs have been identified.

Generally, in the mechanism of HO-catalyzed heme cleavage to $\alpha$-isoform of biliverdin, $\mathrm{CO}$ and iron is universal among bacteria, fungi, plants, insects, and mammals. However, some differences might be present, when cofactor requirements or overall functional significance of heme metabolism between various organisms are discussed.

In D. melanogaster, HO-1 homolog (dHO) has been shown to degrade heme to biliverdin, $\mathrm{CO}$ and iron in the presence of reducing systems such as NADPH/cytochrome $\mathrm{P} 450$ reductase and sodium ascorbate, although the reaction rate is slower than that of mammalian HOs [98]. Interestingly, three isomers of biliverdin, biliverdin-IX $\alpha$ and two other isomers (IX $\beta$ and IX $\delta$ ) are formed [98]. dHO has been shown to be not induced by stress stimuli; however, it is expressed in the brain in the circadian pattern [99, 100]. ho knockdown is lethal at larval stage, what suggests that $\mathrm{dHO}$ is essential for normal development [99]. The tissue-specific ho knockdown in the eye imaginal disc causes abnormalities in the eye morphology as well as of iron accumulation in the compound eye of adult flies. Surprisingly, heme is not accumulated in dHO-deficient tissues, due to decrease in the heme biosynthesis pathway, because the expression of delta-aminolevulinic acid synthase, the first enzyme of the heme-biosynthetic pathway is lowered in larvae as well [99].

In plants, the first $\mathrm{HO}$ homolog was identified in the red algae Cyanidium caldarium [101] and this enzyme was shown to generate biliverdin-IX $\alpha$ that is utilized for the phycobilin synthesis instead of the bilirubin production (generally, plants which lack the equivalent of mammalian BVR do not produce bilirubin) [102]. In Arabidopsis thaliana, HY1 gene encodes a homolog of HO-1, and shows high sequence similarity to mammalian and cyanobacterial HOs as well as it possesses $\mathrm{HO}$ activity in vitro [103]. This homolog utilizes ferredoxin as the reducing partner instead of NADPH:cytochrome P-450 reductase [103], to generate biliverdin-IX as a precursor for the synthesis of light-harvesting pigments. Further analysis 
has underlined the existence of four members of HO family in Arabidopsis thaliana (HY1, HO2-4) [104]. Two subfamilies based on amino acid sequence alignments have been proposed: one subfamily includes $\mathrm{HY} 1, \mathrm{HO} 3$, and $\mathrm{HO} 4$ with the canonical $\mathrm{HO}$ active site, and another subfamily contains just $\mathrm{HO} 2$, which lacks the conserved histidine residue considered to be an important ligand for heme binding. The differences in the level of specific members were studied by Matsumoto et al. who showed that in Arabidopsis HO1 is the highly expressed, followed by lower level of $\mathrm{HO} 2$ and the lowest $\mathrm{HO} 3$ and HO4 [105].

In plants, the up-regulation of HO1 was observed in response to many agents, including light, UV, ROS, iron deprivation or cadmium (Cd), leading to the increased biosynthesis of phytochrome (phy) chromophore and thus being essential for proper photomorphogenesis. HO1 can also play a role in the protection against oxidative stress. For example, in soybean nodules, the treatment with $200 \mu \mathrm{M} \mathrm{Cd}$ caused tenfold induction of $\mathrm{HO}$ activity along with increased oxidative stress. Importantly, co-administration of $10 \mu \mathrm{M}$ biliverdin completely prevented the effects caused by $\mathrm{Cd}$, indicating a potent anti-oxidant activity of BV. On the other hand, the application of zinc protoporphyrin (ZnPPIX), an HO-1 inhibitor, significantly enhanced oxidative stress parameters [106].

Of note, heme oxygenases are present in prokaryotes as well (for review see [107]). Cyanobacterial HOs, e.g., isolated from Synechocystis sp. PCC6803, HO-1 and HO-2 are the best characterized bacterial HOs. In heme-utilizing bacterial pathogen Corynebacterium diphtheriae, $\mathrm{HmuO}$ enzyme has been shown to share $33 \%$ sequence identity and $70 \%$ homology to the human HO-1 [108]. On the other hand, HemO identified as the gene involved in the utilization of the host's heme as an iron source and isolated from Gram-negative pathogen Neisseriae meningitides shows low sequence identity to other HOs [109].

The key functions in the catabolism of heme, regulation of oxidative stress, synthesis of phytobilins, bacterial pathogenesis and iron acquisition are only some of the numerous biological roles played by HOs in prokaryotes and eukaryotes.

\section{Cnc transcription factors may play a special role as pro-longevity and anti-aging factors}

Nrf2 has been suggested as "a guardian of health span and gatekeeper of species longevity" [110]. Also in D. melanogaster $\mathrm{CncC}$ was demonstrated to be involved in aging processes, since older flies progressively lose the ability to CncC-targeted activation in response to stress. On the other hand, the expression of $\mathrm{CncC}$ target genes in unstressed conditions does not decrease in older flies [111].
Several mouse models of extended longevity have been utilized to check the role of Nrf2 in this process. The study performed in mice under calorie restriction, which is known to extend lifespan and delay many aspects of aging [112], showed that the lack of Nrf2 does not attenuate lifespan extension [113]. On the other hand, Nrf2 was prerequisite for cancer-preventive effects after the reduction of calories by $20-40 \%$ [113]. However, experiments performed on $C$. elegans, indicate that the extended longevity of diet-restricted worms results from SKN-1 acting in special neurons, the ASIs. They signal to peripheral tissues to increase their metabolic activity [20]. The recent study by Smith-Vikos et al. identified the specific microRNAs that are critical for the dietary restriction-induced lifespan extension in C. elegans. miR-71 and miR-228 are induced by the calorie restriction and the regulation of these microRNA depends on SKN-1 [114]. Importantly, miR-71 has been shown to promote longevity because miR-71 lossof-function mutants have significantly shorter lifespan than wild-type, and overexpressing miR-71 increases lifespan [115].

SKN-1 mutants have the shortened lifespan and oppositely, overexpression causes the extension of lifespan [18, 116]. Moreover, similarly to Drosophila, the expression level of SKN-1-regulated genes decreases with aging. SKN-1-mediated regulation of collagen expression which is necessary to extracellular matrix remodeling seems to be very important for aging and longevity [117]. This process is connected with the reduced insulin signaling in older animals, which normally regulates SKN-1 activity [118, 119]. SKN-1 is also involved in lifespan extensions in response to reduced activity of the mechanistic target of rapamycin (mTOR) signaling [120, 121].

Palikaras et al. showed that longevity depends on homeostasis between mitophagy (an autophagy type targeting mitochondria for degradation) and mitochondrial biogenesis in C. elegans. This process is regulated by SKN1 by enhancing DCT-1 expression, a $C$. elegans homolog of mammalian BNIP3 and BNIP3L/NIX, key mediators of mitophagy [122, 123], for review see [124].

Interestingly, in the model of Keap1 inactivation in $D$. melanogaster, males showed the higher survival rate after paraquat (a free radical generator) exposure. Moreover, under standard culture conditions, male keap1 $1^{-/+}$ heterozygote flies live significantly longer than their sibling controls [29]. In addition, in Ames dwarf mice and Little mice, the models of delayed aging, showing significant increases in lifespan (50 and $25 \%$, respectively), the enhanced activity of detoxification enzymes and antioxidant proteins including GST (Nrf2-target gene) in comparison with their control counterparts was observed [125]. The recent study performed in ten rodent species, ranging in the maximum lifespan potential (MLSP) 
Fig. 6 Nrf2 activity decreases with aging. Age-related changes in the Nrf2 regulatory system, including increase in Bach1 and Keap1 lead to the inhibition of Nrf2 activity and downstream effects

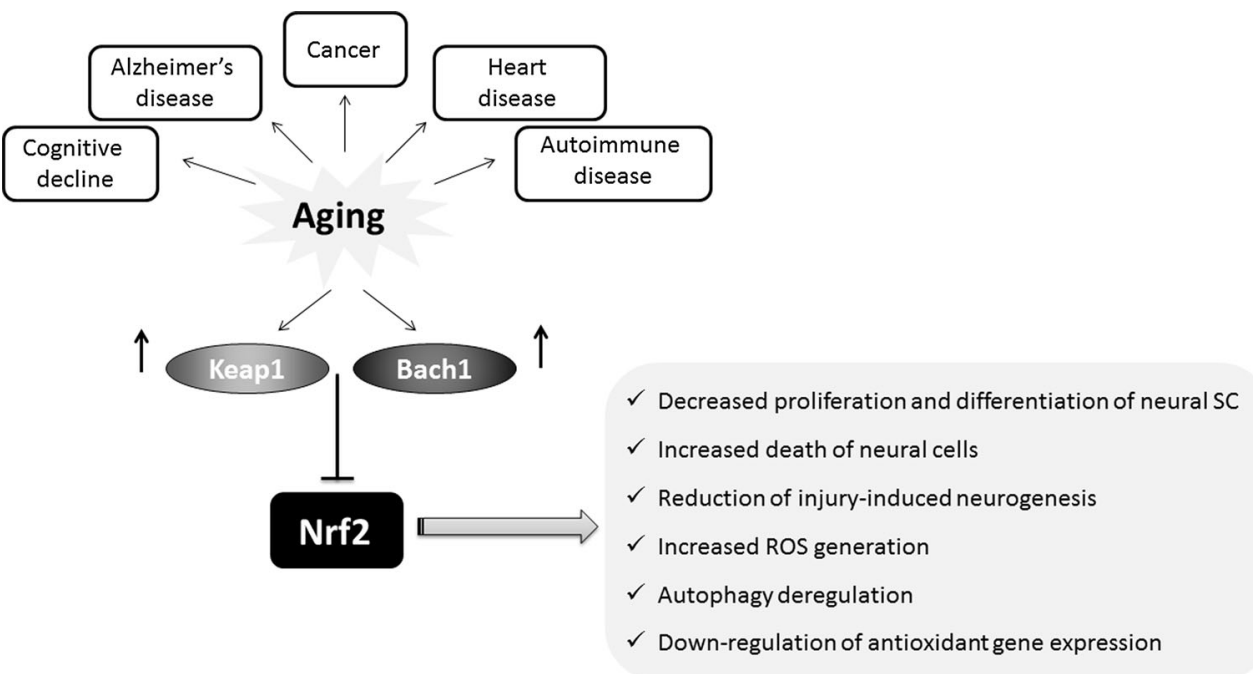

between 4 and 31 years, has shown that in the long-lived naked mole rats there is a constitutively high level of Nrf2 in comparison to other rodent species with shorter lifespan [126]. On the other hand, Keap1 inhibitory protein was negatively correlated with MLSP in rodents, and it was almost not detected in liver of naked mole rats, whereas in laboratory mice Keap1 effectively halts Nrf2 activity [126]. The level of Nrf2-regulated genes, like those encoding HO1, NQO1 or GSTA1, was also potently increased in naked mole rats in comparison to normal-living mice [126]. The summary of age-related changes in the Nrf2 regulatory system is shown in Fig. 6.

\section{Role of CncC/SKN-1/Nrf2 in proteasome regulation}

During aging, a multifactorial process modulated by the interplay between genetic and environmental factors, the functionality of proteasomes declines in both the somatic tissues of Drosophila [127] and in mammalian cells [128]. The proteasome $26 \mathrm{~S}$ is a complex of proteins composed of the proteolytic core (20S protein) flanked by regulatory particles, mostly ATPases (19S proteins), which acquire substrates and direct them into the proteolytic chamber. The $26 \mathrm{~S}$ proteasome is mostly involved in the ATP-dependent degradation of normal short-lived ubiquitinated proteins, whereas the $20 \mathrm{~S}$ proteasome itself degrades oxidized or damaged proteins [129]. A protein that is targeted for degradation is modified by E1, E2, E3 enzymes binding ubiquitin and a poly-ubiquitin chain is attached to the target protein. The $26 \mathrm{~S}$ proteasome recognizes the polyubiquitin chain linked to the target protein and marks it as a substrate for hydrolysis (Fig. 7). This pathway is involved in the regulation of numerous cellular mechanisms, including protein quality control, transcription, cell-cycle regulation, DNA repair, signal transduction, antigen presentation and degradation of mutated proteins involved in the progression of many disorders, e.g., tumor development [130].

In Drosophila, CncC was identified as a candidate transcriptional regulator of proteasome component expression [131]. ARE-enhancer sequences, a target for CncC, are present in proteasome genes Rpnl and Beta-2, within location described as crucial for induction of proteasome gene transcription after treatment with an inhibitor in experimental conditions [132]. $\mathrm{CncC}$ is also involved in the increased 20S and p97 ATPase expression, but does not affect 26 S. Similarly to mammals, Drosophila cells that are pre-treated with hydrogen peroxide adapt to oxidative stress by CncC-dependent up-regulation of the proteolytic activity and $20 \mathrm{~S}$ proteasome expression [133]. Finally, it has been shown that age-dependent decrease in proteasome expression is related to $\mathrm{CncC}$ dysfunction in older flies [127, 134]. Tsakiri et al. showed that knockdown of $20 \mathrm{~S}$ proteasome subunits causes lethality of larva [134]. The proteasome dysfunction observed in adults promotes "oldage" phenotypes and reduces the lifespan. These changes result from dysfunctions of $\mathrm{CncC}$ as $c n c C$ silencing reduced proteasome activity, stress resistance and longevity, while $c n c C$ up-regulation had the opposite effect. Interestingly, the prolonged $c n c C$ overexpression reduces longevity [134]. In another paper, Tsakiri et al., it was demonstrated that proteasome genes are differentially expressed in somatic and reproductive aged tissues and these changes are Cnc/Keap1-dependent [127]. Gonads of young flies had more active proteasomes than somatic tissues, and they were, independently of age, more resistant 


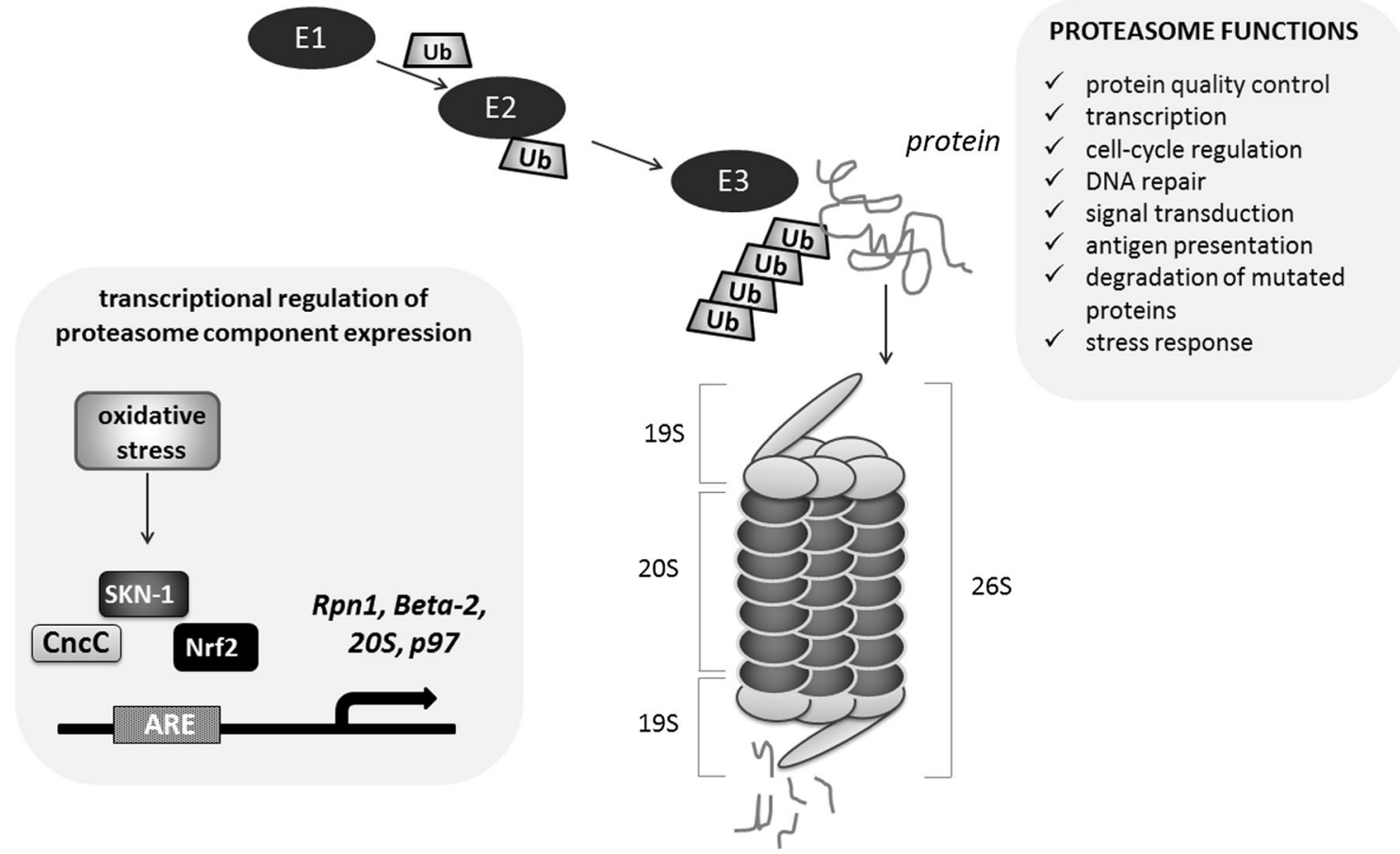

Fig. $7 \mathrm{CncC} / \mathrm{SKN}-1 / \mathrm{Nrf} 2$ involvement in the regulation of proteasome. The Nrf2-dependent up-regulation of the proteasome levels, assembly, and activity may result in the adaptation to stressful

conditions, lifespan extension and increased resistance to stress. The regulation of proteasome genes (Rpn1, Beta-2, 20S, p97) is indicated

to oxidative stress. Additionally, the knockdown of keap1 caused youthful proteasome gene expression level in aged somatic tissue, whereas $\mathrm{cncC}$ silencing resulted in the decreased proteasome gene expression in aged gonads, similar to that observed in normal aged somatic tissues. These findings explain the mechanism of "immortality" of reproductive cells, in which proteasome gene expression is high even in old animals [127].

The mechanism of enhanced proteasomal activity by Nrf2-induced gene expression represents the fundamental strategy in the protection against oxidative stress not only in flies, but also in nematodes and mammals. The worm orthologue of Nrf2, SKN-1 can promote longevity under reduced insulin/IGF-1-like signaling, dietary restriction, and normal conditions [116, 135].

SKN-1 and Nrf2 are involved in the adaptation to stressful conditions through the induction of the $20 \mathrm{~S}$ proteasome [133]. In their recent study, Chondrogianni et al. demonstrated that up-regulation of the $20 \mathrm{~S}$ proteasome levels, assembly, and activity results in C. elegans lifespan extension and increased resistance to stress [136]. Noteworthy, the extension of lifespan was dependent on the transcriptional activity of SKN-1 as well as the other factors like Dauer formation abnormal/Forkhead box class $\mathrm{O}$ (DAF-16/FOXO), and heat shock factor-1 (HSF-1) [136]. The involvement of DAF-16 (FOXO) in SKN-1 effects was also suggested by Wang et al. [135]. In mammalian cells, the activation of $\mathrm{Nrf} 2$ by sulforaphane (SFN) leads to increase of $20 \mathrm{~S}$ proteasomal activity and to augmented expression of the 20S catalytic subunit gene, PSMB5 but this regulation is not present in the fibroblasts from $\mathrm{Nfe} 2 \mathrm{l2}$ disrupted mice [137]. Not only the $20 \mathrm{~S}$ proteasome, but also increased level of the Pa28 $\alpha \beta$ (or 11S) proteasome regulator was reported to be regulated by $\mathrm{Nrf} 2$ as the adaptive response of the cells.

\section{Role of Nrf2/HO-1 in age-dependent diseases}

As mentioned above, Nrf2 signaling pathway is essential for xenobiotic and oxidative stress responses and it plays a protective role in many different organs, and prevents kidney, liver, nervous system, lungs and other organs from the toxic insults. As oxidative stress is believed to contribute to aging, it could be easily predicted that Nrf2 system may function in the prevention of age-related diseases. Moreover, as discussed earlier, increasing proteasome activity might represent anti-senescence therapy and the defective ubiquitin/proteasome pathway leading to protein aggregates that is observed in many neurodegenerative disorders, suggesting a possible protective role of Nrf2/HO-1 system. 


\section{Neurodegeneration}

The basic research on the role of Nrf2 in astrocytes, neurons and other neuronal cells indicates the neuroprotective role of this transcription factor. Importantly, aging may affect Nrf2 level, and the reduction of Nrf2 mRNA and protein results in impaired Nrf2 signaling. Suh et al. [138] indicated that the level of Nrf2 and the expression of Nrf2mediated $\gamma$-glutamylcysteine ligase (GCL) and glutathione (GSH) level in old (24-28 months) rats decrease potently in comparison to young (2-5 months) animals. In 2009, Duan et al. using in vitro and in vivo models, clearly showed that with aging, the level of Nrf2 as well as Nrf2dependent genes, including HO-1, decreases in the mouse spinal cord and astrocytes [139]. Moreover, Suzuki et al. have found that Nrf2 level decreases in macrophages from older smokers in comparison with older nonsmokers. Simultaneously, the level of Keap1 and Bach1, the Nrf2 repressors increases in lungs [140].

The augmented oxidative stress is associated with death of cells of the nervous system in the pathogenesis of neurodegenerative diseases such as Alzheimer's disease (AD), Parkinson's disease (PD), Huntington's disease (HD) or amyotrophic lateral sclerosis (Lou Gehrig's disease). In vitro studies clearly indicate that chemical inducers of Nrf2, like tBHQ and SFN or its adenoviral overexpression in astrocytes results in protection against hydrogen peroxide-induced oxidative stress $[141,142]$. On the other hand, experiments performed in Nrf2-deficient cells and $\mathrm{Nrf} 2$ knockout mice showed they are significantly more vulnerable to striatal damage reminiscent of HD [143]. A similar increase in the sensitivity of the Nrf2-deficient mice has been observed in models of PD. The neurotoxin 6-hydroxydopamine (6-OHDA) both in vitro and in vivo showed a greater effect in Nrf2-deficient cells than in wildtype counterparts [144]. Similarly, in the 1-methyl-4-phenyl-1,2,3,6-tetrahydropyridine (MPTP) animal model of $\mathrm{PD}$, the greater loss of dopamine transporter levels in the striatum of Nrf2 knockout mice than in wild-type at all MPTP doses tested was observed [145, 146]. Moreover, Nrf2 activation by SFN protects against MPTP-induced death of nigral dopaminergic neurons, leading to decrease in astrogliosis, microgliosis, and release of pro-inflammatory cytokines [147]. Interestingly, $\mathrm{HO}-1^{-1-}$ mice have been shown to be similarly sensitive to MPTP as wild-type littermates [146], although the previous studies showed ample evidence for neuroprotective activities of HO-1, e.g., adenoviral overexpression of HO-1 increased significantly the survival rate of dopaminergic neurons in the rat model of PD [148]. Of note, as mentioned above, some studies indicate that carriers of $-413 \mathrm{~A} / \mathrm{T}$ SNP in $\mathrm{HO}-1$ together with TT genotype of GSK3 $\beta$ had four times higher risk of developing PD than subjects without these genotypes [89].
In flies, $\mathrm{CncC}$ can also protect from neurodegeneration, as it has been shown in the Drosophila model of PD. The chemical agents, SFN and allyl disulfide, inhibit neurodegenerative changes by induction of $\mathrm{CncC}$ activity [149]. It has also been shown that decaffeinated coffee and nicotine-free tobacco (but not caffeine and nicotine alone) have neuroprotective effect on flies with overexpression of human $\alpha$-synuclein or in parkin mutant (models of PD), as well as in the fly's models of AD and polyglutamine disease. This effect is mediated by $\mathrm{Cnc}$, as it has been proved by silencing $c n c$ transcripts that suppressed the cytoprotective effect of coffee and tobacco. Moreover, the Cnc activator present in coffee, called cafestol, is able to protect neuronal cells against death in transgenic $\alpha$-synuclein flies. Cafestol can induce gstD1GFP that is used as a reporter of Nrf2 activity [150]. Barone et al. claim that the $\mathrm{Cnc}$ overexpression in dopaminergic neurons is sufficient to counteract $\alpha$-synuclein toxicity [151]. In the recent paper by Wang et al., transgenic flies with mutated $\alpha$-synuclein (A53T), showing neurodegenerative changes characteristic for $\mathrm{PD}$, were protected by bardoxolone methyl (CDDO-Me), Nrf2 inducer, through ROS scavenging and the activation of Nrf2/antioxidant response element signaling pathway. Furthermore, the selective expression of $\mathrm{CncC}$ in dopaminergic neurons effectively protected against the neurodegenerative phenotype of the A53T $\alpha$-synuclein flies [152].

The involvement of Nrf2 in the AD development seems to be associated with the disease progression. Several studies have shown the increase in the expression levels of Nrf2-target genes, including HO-1 during AD progression $[153,154]$. The another studies showed a potent up-regulation of HO-1 in glial cells of AD patients [155]. In addition, the inhibition of HO-1 by azole-based, a brainpermeable inhibitor of HO-1, OB-28, led to the significant improvement in a complex maze learning task relative to saline-treated controls, indicating the amelioration of behavioral anomalies in the transgenic mouse model of $\mathrm{AD}$ through HO-1 down-regulation [156]. However, in 2007, Ramsey and colleagues have observed the decrease in nuclear Nrf2 expression in the affected brain regions of AD patients [157]. As it was suggested by Yamazaki et al., in the early stages of $\mathrm{AD}, \mathrm{Nrf} 2$ is up-regulated by $\beta$-amyloidinduced ROS, whereas during the disease progression Nrf2 level starts to decrease [158].

The neuroprotective role of Nrf2 is based also on the results from dimethyl fumarate (DMF) action in multiple sclerosis (MS). MS is a chronic, devastating, autoimmune disease manifested by the demyelination of neuronal axons. Inflammation and oxidative stress together with neurodegeneration contribute to disease progression (reviewed in [159]). 


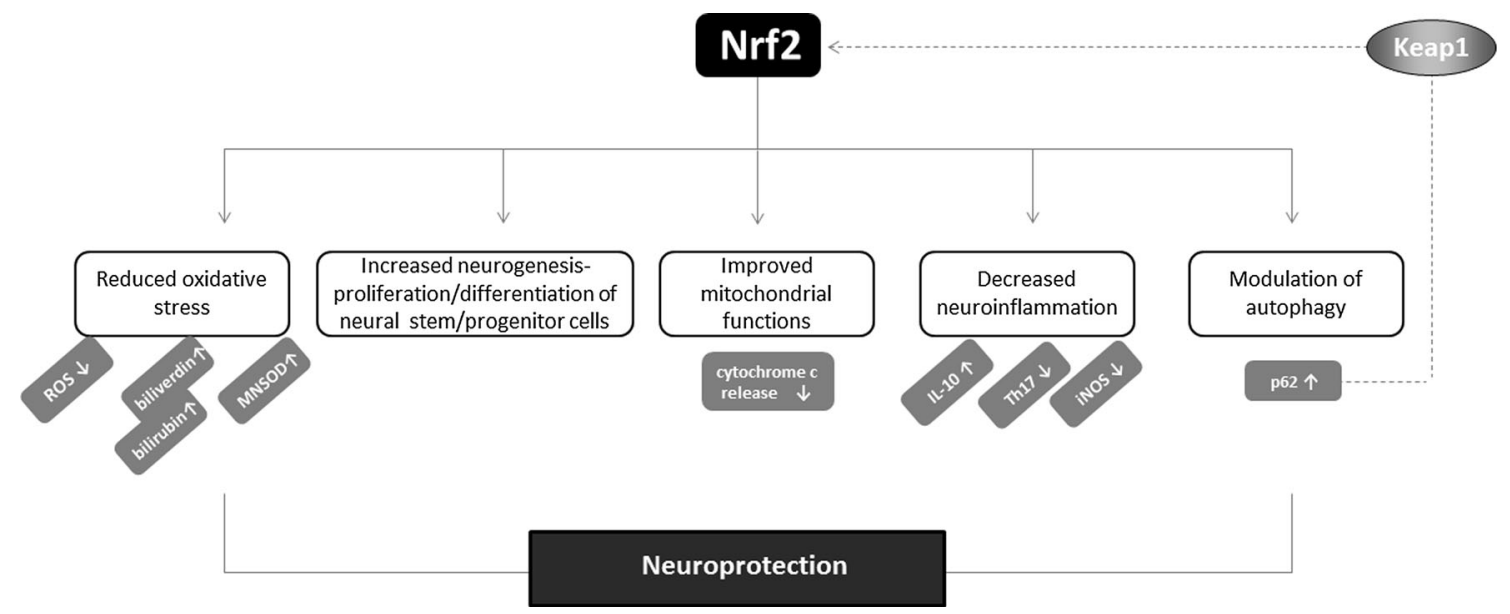

Fig. 8 Neuroprotective activity of Nrf2. Nrf2 mediates neuroprotection through several possible mechanisms. The reduction of oxidative stress, modulation of inflammation as well as autophagy process may

The protective role of DMF in MS pathology is supported by both in vitro and in vivo studies as well as by the results of large clinical trials (CONFIRM and DEFINE) [160]. Based on those experiments it was suggested that DMF does not have a single mechanism of action, but rather exerts a multitude of biological effects. It possess anti-inflammatory potential through shifting the cytokine profile from Th1 toward a Th2 profile as well as it was shown to inhibit the activation of NF- $\kappa \mathrm{B}$ and pro-inflammatory IL-6 and IL-12 (reviewed in [161, 162]). Additionally, in 2011, Linker et al. demonstrated that beneficial effects of DMF in murine experimental autoimmune encephalomyelitis (EAE), a mouse model of MS are mainly due to activation of Nrf2 [163]. Many other papers showed that the regulation of Keap1 and Nrf2 activation, resulting in transcription of HO-1 or NQO1 is responsible for neuroprotective effect of DMF (reviewed in [161]).

Importantly, the DMF analog, BG-12 (brand name Tecfidera $^{\mathrm{TM}}$ ) was approved in 2013 for the treatment of relapsing-remitting MS by the European Union and the US Food and Drug Administration [160]. Not only MS patients may be treated by DMF, as it reduces psoriasis symptoms [164] as well it might protect against systemic and CNS complications in HIV infection through its effective suppression of immune activation, oxidative stress, HIV replication, and macrophage-associated neuronal injury [165].

Several possible mechanisms could be responsible for the neuroprotective activity of Nrf2 (Fig. 8). First of all, the induction of protective genes, like those encoding HO-1 and GCL or GSH synthetase may be a major component of the protection against oxidative stress exerted by $\mathrm{Nrf} 2$ [142]. Nrf2 is also crucial for injury-induced neurogenesis contribute to protective effects of $\mathrm{Nrf} 2$ in the nervous system. Of note, p62 may directly activate Nrf2 through sequestration of Keap1

in the hippocampus, regulating proliferation and neuronal differentiation of neural stem/progenitor cells [166]. Possibly, Nrf2 may protect from mitochondrial dysfunction and prevent from increased ROS generation and death of neural cells. In addition, the control of neuroinflammation by $\mathrm{Nrf2}$, and the inhibition of pro-inflammatory factors, like IL-6 or iNOS as well as the up-regulation of antiinflammatory IL-10 may contribute to this effect. Moreover, Nrf2 may modulate autophagy since defective autophagic system is known to be pathogenic in neurodegenerative disorders like AD [167].

As mentioned above, under normal conditions, Nrf2 is bound to Keap1 and is inactivated as a transcription factor for antioxidant defense genes by proteasome-mediated degradation. Under oxidative stress, Keap1 can be modified through oxidative-dependent mechanism and it can no longer bind Nrf2. It might also be sequestered by p62, a ubiquitin-binding protein acting as a scaffold for several protein aggregates and triggering their degradation through the proteasome, or the lysosome pathway via autophagy $[168,169]$. In 2010, the non-canonical pathway of Nrf2 activation, relying on redox-independent interaction between Keap1 and p62 was suggested [168]. Lau et al. have shown that accumulation of endogenous p62 or ectopic expression of p62 sequester Keap1 into aggregates, resulting in the inhibition of Keap1-mediated Nrf2 ubiquitination and its subsequent degradation by the proteasome [168]. Moreover, phosphorylation of p62 at $\mathrm{Ser}^{351}$ increases its binding affinity for Keap1, leading to the increased expression of cytoprotective Nrf2 targets [170]. Jain et al. identified p62 as a direct Nrf2-regulated gene as Nrf2 binds to ARE sequence in the p62 promoter, leading to its increased expression [171]. In turn, in genetically modified mice with decreased $26 \mathrm{~S}$ proteasome 
activity, the activation of autophagy and the Keap1-Nrf2 pathway represent the defense mechanisms that is able to adapt to impaired proteasome function [172].

\section{Age-related macular degeneration}

Oxidative stress might be also one of the main factors contributing to the pathogenesis of age-related macular degeneration (AMD), characterized by the damage of the retinal pigment epithelium (RPE) cells and photoreceptors (Fig. 9). In aging Nrf2 KO mice degeneration of RPE cells resembling human AMD is evident with defects in lysozyme-dependent degradation leading to less efficient removal of oxidatively damaged protein aggregates through deregulated autophagy [173]. Interestingly, the 25129A $>$ C polymorphism of the Nrf2 gene has been suggested to be associated with AMD [174]. Similarly, the genetic variation in HO-1 gene may affect the pathogenesis of AMD through the modulation of the cellular reaction to oxidative stress. It has been suggested that $19 \mathrm{G}>\mathrm{C}-\mathrm{HO}-1$ polymorphisms may be associated with the occurrence and progression of AMD [175].

The possible link between Nrf2, AMD and cigarette smoking, the latter known to be involved in the pathology of AMD [176], has been studied by Wang et al. [177]. Indeed, Nrf2 deficiency magnified the effect of cigarette smoking on inflammatory response and complement activation, the effects contributing to drusen formation
[177]. On the other hand, in vitro experiments performed on ARPE-19 cells exposed to cigarette smoke extract (CSE) or hydroquinone (HQ), a component of cigarette smoke, showed that the increased oxidative damage and apoptosis, is manifested by HO-1 up-regulation and possibly iron accumulation [178]. Given the evidence that iron accumulation within the eye may account for pathological progression of AMD [179], the very high activity of HO- 1 caused by CSE may affect AMD pathology.

The direct comparison of young (2 months) and old (15 months) mice under unstressed and sodium iodatestressed conditions, that is the frequently used model for the retinal degeneration [180], have underlined the involvement of Nrf2 signaling in the pathogenesis of the disease [181]. The retinal pigment epithelium of old mice exhibited impaired induction of Nrf2-dependent genes in response to the toxic insult. On the other hand, genetic enhancement of Nrf2 activity by the conditional knockdown of the Nrf2 negative regulator Keap1, partially restores Nrf2 signaling through the increased NQO1 expression in old mice [181].

\section{Cancer}

Growing body of evidence suggests that $\mathrm{Nrf} 2$ is involved in the chemoprevention of normal cells but also promotes the growth of cancer cells. Similarly, HO-1 involvement in
Fig. 9 Age-related macular degeneration and Nrf2.

Decrease in Nrf2 and increase in

Keap1 levels as well as Nrf2 and HO-1 promoter polymorphism contribute to damage of the retinal pigment epithelium (RPE) cells and photoreceptors. Nrf2 deficiency leads to increased oxidative stress and deregulated autophagy magnified the accumulation of protein aggregates and drusen formation

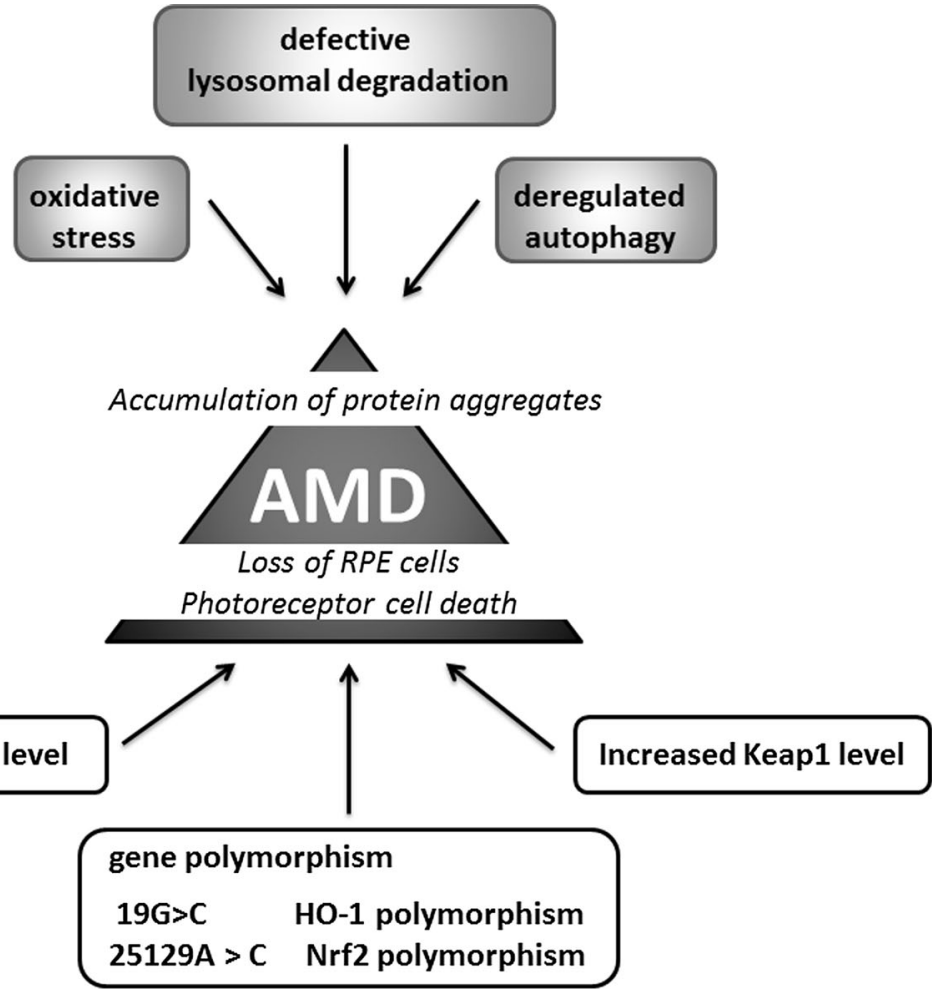


cancer progression is well documented, but also HO-1 may be protective for cancer cells at least in some tumor types.

Noteworthy, ROS are involved in both tumor initiation as well as in tumor progression, causing nucleic acid alterations, both sugar and base modifications in nuclear but also in mitochondrial DNA that is more prone to mutations due to the lack of histones [182]. In tumors, the production of ROS is exacerbated through the increased mitochondrial activity and accelerated metabolism of tumor cells. ROS scavenging through the Nrf2-mediated induction of target genes might be a protective mechanism of action of many natural and synthetic compounds used as chemopreventive agents, which are able to stop or delay the occurrence of malignancy (Fig. 7). The examples include oltipraz, oleanolic acid (OA) and its synthetic derivatives, like CDDO-imidazole (CDDO-Im) (1-[2-cyano-3-,12-dioxooleana-1,9(11)-dien-28-oyl] imidazole) or SFN (reviewed in $[183,184])$. In our hands, some synthetic derivatives of OA increased Nrf2 activity and its target gene expression, but we also observed cell-type specific response to other triterpenoid, betulin on Nrf2 activation in keratinocytes and endothelial cells [183]. Additionally, the beneficial, Nrf2dependent effects have been clearly presented in many in vitro and in vivo studies also using Nrf2-deficient cells/ animals. The effectiveness of Nrf2 inducers has been assessed in clinical trials. However, oltipraz as well as the CDDO-derivative, bardoxolone methyl, because of serious side effects reported in some trials, like BEACONbardoxolone methyl evaluation in patients with chronic kidney disease and type 2 diabetes (ClinicalTrials.gov, NCT01351675), have been withdrawn from clinics. The plethora of data from Nrf2 $\mathrm{KO}$ mice suggest greater susceptibility of such mice to carcinogenic insults, like $N$-nitrosobutyl(4-hydroxybutyl)amine $\quad(\mathrm{BBN})$-induced bladder carcinogenesis [185], aflatoxin-induced human hepatocellular carcinomas (HCCs) [186] or ultraviolettriggered skin carcinogenesis [187].

Although the positive, protective effect of Nrf2 has been reported mostly during tumor initiation, it is now well documented that this transcription factor has a dual role in tumorigenesis. In the last years, an increasing number of studies have examined the oncogenic properties of Nrf2 (reviewed in [188]) as shown in lung cancer [189], squamous cell carcinomas of esophagus and skin [190] or hereditary leiomyomatosis and renal cell cancer (HLRCC) [191]. HLRCC is caused by a mutation of fumarate hydratase (FH), the Krebs cycle enzyme, functioning as a tumor suppressor gene and the inactivation of $\mathrm{FH}$ initiates formation of multiple renal cysts. Adam et al. showed that the formation of cysts in FH-deficient mice is dependent on Nrf2 and on the modification of Keap1 [191]. In lung cancer, loss of Keap1 function leading to constitutive activation of Nrf2-mediated gene expression caused enhanced transcriptional induction of antioxidants, xenobiotic metabolism enzymes, and drug efflux pumps and promotes tumorigenesis [189]. Of note, mutation of Keap1 leading to its inactivation is a frequent genetic alteration in non-small-cell lung carcinoma (NSCLC) [189].

Similarly, HO-1 demonstrated pro-tumorigenic effects in many cancers. HO-1 was shown to increase tumor cells proliferation and migration and prevent cancer cells from apoptosis and autophagy (for review see [192]). The regulation of blood vessel formation and the increase in the expression of pro-angiogenic factors are also regulated in HO-1 dependent way ([193-195], reviewed in [67, 196]). The positive correlation between the progression of tumors and increased HO-1 expression was noted for many tumors, including prostate cancer, renal cancer, glioma, melanoma, pancreatic cancer, Kaposi sarcoma and others (for review see [196]).

Recent studies underlined the possible link between oncogenic mutations and HO-1 induction. Hmox-1 gene expression is induced upon expression of oncogenes associated with the induction of some types of cancer. In Kaposi sarcoma, HO-1 mediates the oncogenic $\mathrm{G}$ proteincoupled receptor (vGPCR) oncogene-induced transformation associated with the increased vascular endothelial growth factor (VEGF) synthesis [197, 198]. The other study indicates the link between HO-1 and Bcr/Abl fusion gene in chronic myelogenous leukemia (CML) [199], whereas in kidney cancer the activation of Ras pathway and the stimulation of downstream signaling, including Raf and ERK, lead to Nrf2 activation and HO-1 induction [200]. In addition, Drosophila was used as a model for studying link between Myc, a pro-oncogenic transcription factor which has been found to be deregulated in a large number of different cancer types, and Nrf2. Nagy et al. have reported that the activation of $\mathrm{Cnc} / \mathrm{Nrf} 2$ is required for Myc-induced overgrowth and this effect is related to the autophagy unfolded protein response induction, p62 accumulation and Nrf2 activation [201]. In 2010 it was already published, that p62 activation, through the constant activation of antioxidant response via the disruption of the interaction between Keap1 and Nrf2, leads to tumorigenesis [169]. The Myc-induced overgrowth in Drosophila is a consequence of both increased autophagy and antioxidant response. In mammals, the direct interaction of c-Myc and Nrf2 and c-Myc-dependent negative regulation of phase II genes was demonstrated [202]. The cross-talk between Nrf2 and other transcription factors playing an important role in cancer cell biology has to be also underlined. We have demonstrated that the regulation of pro-angiogenic IL-8 expression by HIF-1 and HIF-2 transcription factors requires Nrf2 as well as c-Myc factors [203].

Not only pro-tumoral effects of HO-1 are described; due to its antioxidant and genome protecting activities, HO-1 


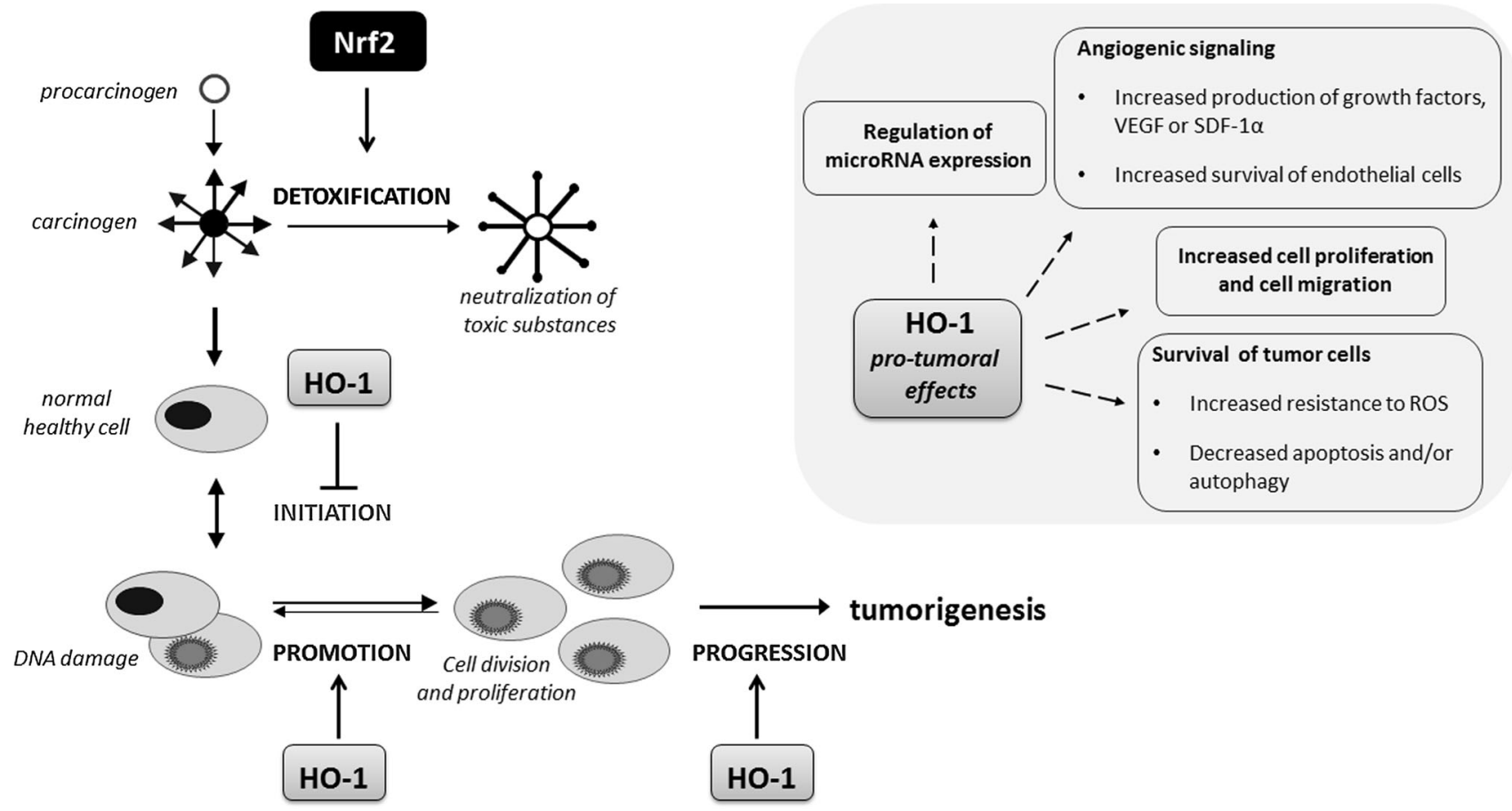

Fig. 10 Role of Nrf2/HO-1 in tumor initiation and progression. Both Nrf2 and HO-1 may decrease tumor initiation through the detoxification and ROS scavenging mechanisms. On the other hand, this cytoprotective system exerts stimulatory effect on the progression of tumors mostly due to its anti-apoptotic, pro-angiogenic, pro-migratory and modulatory influence on the expression of microRNAs. However, in some tumors the opposite, inhibitory effect on progression of tumors have been reported may exert the protective effects against carcinogens and may reduce the probability of tumor initiation (Fig. 10). In agreement with that, we have observed that HO-1 may protect healthy tissues against chemical induction of squamous cell carcinoma, but in already growing tumors HO-1 accelerates its progression toward more malignant forms [204]. The dual role of HO-1 and its products, mostly $\mathrm{CO}$, in tumorigenesis depending on tumor type and the balance between anti-angiogenic and proangiogenic pathways activated in tumors by HO-1 was described in several review papers including our recent review [70] and summarized also in Fig. 10.

\section{Nrf2 as a factor contributing to reductive stress}

As mentioned above, Nrf2 is protective gene; however, recent studies underline the fact that its constant overexpression might be detrimental. Wakabayashi et al. observed that deletion of Keap1 leads to Nrf2 accumulation in nucleus at constitutively high levels and the overproduction of cytoprotective enzymes. Unexpectedly, Nrf2 accumulation was not protective, but postnatal lethality was observed as the result of Keap1 deletion [205]. Recent studies focused at the understanding of this phenomenon, and the involvement of Nrf2 in so-called reductive stress was suggested. Reductive stress is induced by conditions which promote the formation of excessive intracellular $\mathrm{NAD}(\mathrm{P}) \mathrm{H}$ together with enormous activation of antioxidant system and suppressed oxidative activity (reviewed in [206]). The increased level of GSH, Nrf2 target gene, might also act as a reducing equivalent, similar to NAD(P)H. In fact, it was shown that the deleterious effects of reductive stress were associated with dysregulation of glutathione homeostasis (increased GSH level and ratio of GSH/GSSG) and protein aggregation cardiomyopathy in experimental mice model [207, 208]. Further experiments identified Nrf2 as a factor contributing to reductive stress in the human mutant protein aggregation cardiomyopathy (MPAC) in mice [209]. Moreover, using MPAC transgenic mice, Kannan et al. evidenced that attenuation of Nrf2 signaling prevents from reductive stress. Genetic deletion of Nrf2 in such transgenic MPAC animals reduces aggregation of toxic mutant proteins and prevents pathological cardiac remodeling caused by reductive stress [210]. The possible involvement and underlying mechanisms of Nrf2dependent reductive stress is summarized in recent review by Narasimhan and Rajasekaran [206].

In summary, the maintaining Nrf2-Keap1 activity at optimal levels to deal with both oxidative and reductive stress and maintaining proper redox homeostasis is crucial for the proper cell functioning. 


\section{MicroRNAs and Nrf2/HO-1 system}

As microRNAs are the master regulators of gene expression and their level is frequently altered in age-related disorders like cancer or neurodegenerative diseases, it could be easily predicted that these small regulatory RNA molecules serve important functions in modulating the Nrf2/HO-1 signaling pathway (Fig. 11). However, the role of microRNAs in the regulation of Nrf2 expression has been studied in limited number of publications. Chorley et al. using ChIP-seq analysis identified several microRNAs which may potentially regulate Nrf2 activity [211]. The direct evidence of Nrf2 regulation by the specific microRNAs has been shown by Eades et al. who found that miR-200a that targets Keap 1 is a regulator of Nrf2 activation in breast cancer cells [212]. On the other hand, miR-28 regulates Nrf2 in a Keap-1independent way by targeting the $3^{\prime} \mathrm{UTR}$ of Nrf2 mRNA and decreases Nrf2 expression in mammary epithelial cells [213]. Another microRNA shown to inhibit Nrf2 mRNA expression through direct effect on $3^{\prime} \mathrm{UTR}$ in Nrf2 mRNA was miR-144 [214].
Nrf2-dependent regulation of the microRNAs important for some aspects of tumorigenesis has been identified. For example, Nrf2 abrogates mir-1 and miR-206 and affects lung carcinoma metabolism by reprogramming glucose metabolism toward the pentose phosphate pathway (PPP) and the tricarboxylic acid (TCA) cycle [215]. Similarly, we showed the inhibitory effect of HO-1 on myomirs, including miR-206 expression in $\mathrm{C} 2 \mathrm{C} 12$ cells, and myoblast differentiation [216]. Moreover, we have also demonstrated that HO-1 inhibits miR-378 and the interplay between HO-1 and miR-378 significantly modulates NSCLC progression and angiogenesis [217, 218]. Interestingly, although HO-1 enhanced expression of microRNAs processing enzymes (DGCR8, Drosha and Dicer1) in NCI-H292 cell line and increased global amounts of miRNA fraction [217], the expression of some specific microRNAs was inhibited. For example, not only miR-378, but also the expression of other pro-angiogenic microRNAs, such as miR-17-92 and miR-210 were downregulated. On the other hand, anti-angiogenic miR424 was upregulated by HO-1. Consistently tumors from

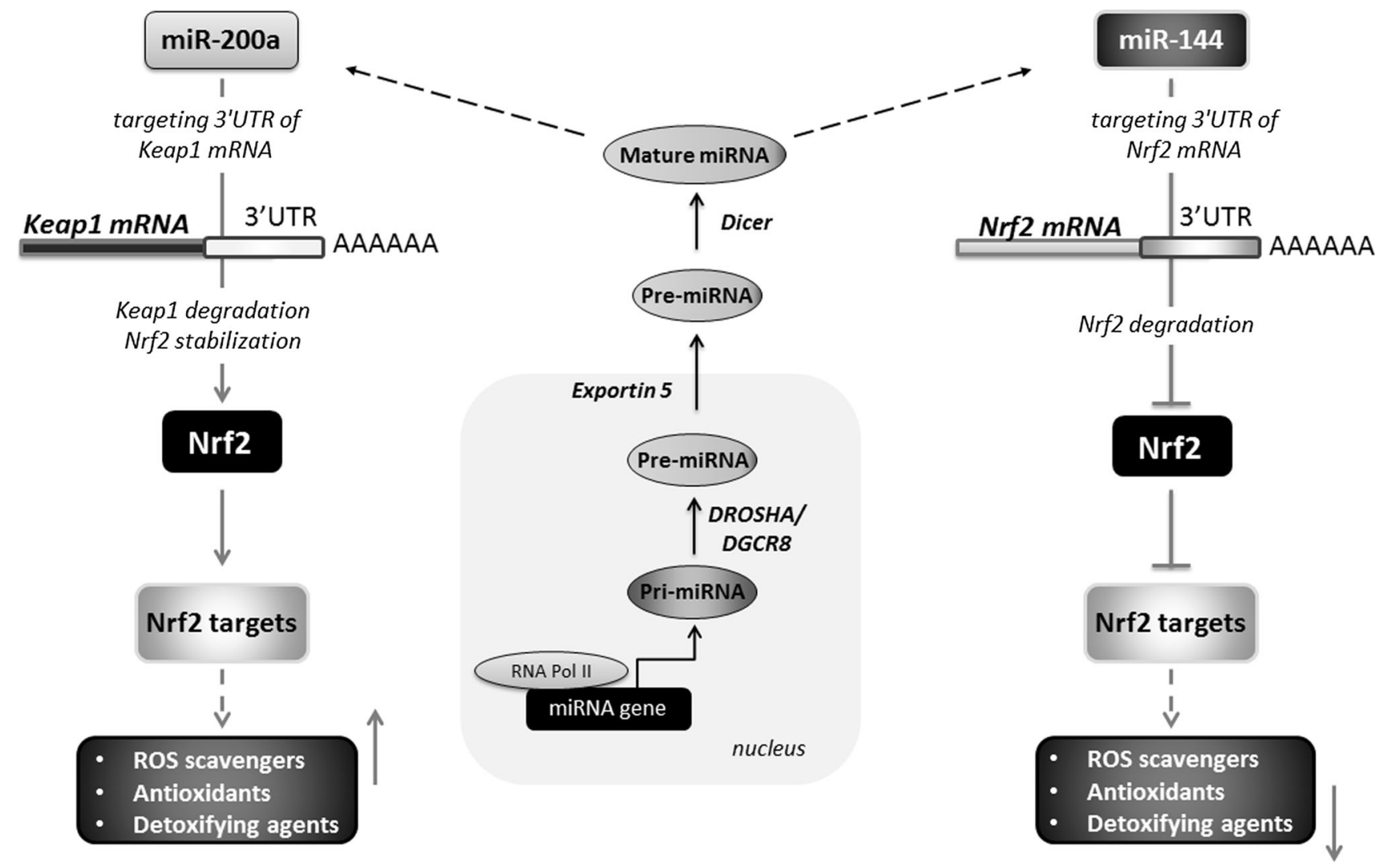

Fig. 11 miRNAs biogenesis and their role in the regulation of Nrf2 expression. microRNAs, transcribed by polymerase II as pri-miRNAs, are cleaved by endoribonucleases Drosha and DGCR8, to be finally exported from the nucleus by exportin-5. An endoribonuclease Dicer processes the pre-miRNA, creating a mature, double-stranded miRNA duplex. Endogenous miRNAs bind to target sequences in the $3^{\prime} \mathrm{UTR}$ regions of their target mRNA to produce translational arrest. Some miRNAs, e.g., miR-200a can target Keap1 mRNA, leading to its degradation and up-regulation of Nrf2 targets. On the other hand, miR-144 can affect Nrf2 level in a Keap1-independent manner but through direct targeting the $3^{\prime} \mathrm{UTR}$ of Nrf 2 mRNA causing the downregulation in $\mathrm{Nrf} 2$ expression 
HO-1 overexpressing NCI-H292 cells were less vascularized and grew slower [217].

As mentioned above, Nrf2/HO-1 system plays a pivotal role in neurodegenerative disorders, and a link with microRNAs was found also in this subject. In primary astrocytes overexpressing $\mathrm{HO}-1$, the up-regulation of miR16 , miR-17 and miR-140 with concomitant inhibition of miR-29c, miR-138, miR-181a, miR-187, miR-206 and miR-297 was observed [219]. The changes in the expression of those microRNAs and regulated mRNAs might be responsible for the inflammatory, degenerative and apoptosis-triggered cell death.

All these results concerning the microRNAs regulation further clarify molecular mechanisms by which $\mathrm{Nrf} 2 / \mathrm{HO}-1$ participate in pathogenesis and therapy of stress activated and age-related diseases.

\section{Conclusions}

Nrf2/HO-1 pathways are widely studied in vertebrates. As $\mathrm{SKN}-1$ in $C$. elegans or $\mathrm{CncC}$ in D. melanogaster share high homology with Nrf2, these organisms offer suitable models to study the function and biology of Nrf2 transcription factors. A large number of experiments indicate the importance of $\mathrm{Nrf} 2$ and its equivalents in embryonic development, stress signaling and aging. Moreover, Nrf2-dependent genes, like HO-1 provide cytoprotective effect and play a crucial role in the development of oxidative and age-related disorders. The more detailed analysis of microRNAs involvement in the regulation of Nrf2/HO-1 may provide new ideas for the treatment of abovementioned diseases. The involvement of Nrf2 in the reductive stress in the mouse model of protein aggregation cardiomyopathy suggests the contribution of this transcriptional regulator of antioxidant genes in other pathological situations related to unbalanced redox homeostasis. Although our knowledge about the role of Nrf2 in controlling both physiology and disease progression extended rapidly recently, thanks to model organisms including flies and worms, still the influence of CNC factors on lifespan and health is an attractive scientific problem to resolve.

Acknowledgments The authors' research is supported by the grants from the National Science Centre OPUS No. 2012/07/B/NZ3/02908 (EP), OPUS No. 2012/07/B/NZ1/02881 (JD), MAESTRO No. 2012/06/A/NZ1/0004 (JD), Harmonia No. (2012/06/M/NZ1/00008) (AJ), Harmonia No. 2014/14/M/NZ1/00010 (JD) and National Centre for Research and Development (PBS2/B7/15/2014). The Department of Medical Biotechnology is conducting research with the CNRS (Orleans, France) in the scope of the MiR-TANGo International Associated Laboratory (LIA). The Faculty of Biochemistry, Biophysics and Biotechnology of the Jagiellonian University is a beneficiary of the structural funds from the European Union and the
Polish Ministry of Science and Higher Education (Grant Nos: POIG.02.01.00-12-064/08 and 02.02.00-00-014/08) and is a partner of the Leading National Research Center (KNOW) supported by the Ministry of Science and Higher Education.

Open Access This article is distributed under the terms of the Creative Commons Attribution 4.0 International License (http:// creativecommons.org/licenses/by/4.0/), which permits unrestricted use, distribution, and reproduction in any medium, provided you give appropriate credit to the original author(s) and the source, provide a link to the Creative Commons license, and indicate if changes were made.

\section{References}

1. Kensler TW, Wakabayashi N, Biswal S (2007) Cell survival responses to environmental stresses via the Keap1-Nrf2-ARE pathway. Annu Rev Pharmacol Toxicol 47:89-116

2. Mitsuishi Y, Motohashi H, Yamamoto M (2012) The Keap1Nrf2 system in cancers: stress response and anabolic metabolism. Front Oncol 2:200

3. Kansanen E, Kuosmanen SM, Leinonen H, Levonen AL (2013) The Keap1-Nrf2 pathway: mechanisms of activation and dysregulation in cancer. Redox Biol 1:45-49

4. Sykiotis GP, Bohmann D (2010) Stress-activated cap 'n "collar transcription factors in aging and human disease. Sci Signal 3:re3

5. Kang MI, Kobayashi A, Wakabayashi N, Kim SG, Yamamoto M (2004) Scaffolding of Keap1 to the actin cytoskeleton controls the function of $\mathrm{Nrf} 2$ as key regulator of cytoprotective phase 2 genes. Proc Natl Acad Sci USA 101:2046-2051

6. Kobayashi M, Yamamoto M (2006) Nrf2-Keap1 regulation of cellular defense mechanisms against electrophiles and reactive oxygen species. Adv Enzyme Regul 46:113-140

7. Baird L, Dinkova-Kostova AT (2011) The cytoprotective role of the Keap1-Nrf2 pathway. Arch Toxicol 85:241-272

8. Kobayashi A, Kang MI, Watai Y, Tong KI, Shibata T, Uchida K, Yamamoto M (2006) Oxidative and electrophilic stresses activate Nrf2 through inhibition of ubiquitination activity of Keap1. Mol Cell Biol 26:221-229

9. Canning P, Sorrell FJ, Bullock AN (2015) Structural basis of Keap1 interactions with Nrf2. Free Radic Biol Med 88:101-107

10. Hu C, Eggler AL, Mesecar AD, van Breemen RB (2011) Modification of keap1 cysteine residues by sulforaphane. Chem Res Toxicol 24:515-521

11. Motohashi H, Yamamoto M (2004) Nrf2-Keap1 defines a physiologically important stress response mechanism. Trends Mol Med 10:549-557

12. McMahon M, Thomas N, Itoh K, Yamamoto M, Hayes JD (2004) Redox-regulated turnover of Nrf2 is determined by at least two separate protein domains, the redox-sensitive neh2 degron and the redox-insensitive neh6 degron. J Biol Chem 279:31556-31567

13. Holtzclaw WD, Dinkova-Kostova AT, Talalay P (2004) Protection against electrophile and oxidative stress by induction of phase 2 genes: the quest for the elusive sensor that responds to inducers. Adv Enzyme Regul 44:335-367

14. Li W, Kong AN (2009) Molecular mechanisms of Nrf2-mediated antioxidant response. Mol Carcinog 48:91-104

15. Kobayashi M, Itoh K, Suzuki T, Osanai H, Nishikawa K, Katoh Y, Takagi Y, Yamamoto M (2002) Identification of the interactive interface and phylogenic conservation of the Nrf2-Keap1 system. Genes Cells 7:807-820 
16. Williams LM, Timme-Laragy AR, Goldstone JV, McArthur AG, Stegeman JJ, Smolowitz RM, Hahn ME (2013) Developmental expression of the Nfe2-related factor (Nrf) transcription factor family in the zebrafish, danio rerio. PLoS One 8:e79574

17. Li L, Kobayashi M, Kaneko H, Nakajima-Takagi Y, Nakayama Y, Yamamoto M (2008) Molecular evolution of Keap1. Two Keap1 molecules with distinctive intervening region structures are conserved among fish. J Biol Chem 283:3248-3255

18. An JH, Blackwell TK (2003) SKN-1 links C. elegans mesendodermal specification to a conserved oxidative stress response. Genes Dev 17:1882-1893

19. Glover-Cutter KM, Lin S, Blackwell TK (2013) Integration of the unfolded protein and oxidative stress responses through SKN-1/Nrf. PLoS Genet 9:e1003701

20. Bishop NA, Guarente L (2007) Two neurons mediate diet-restriction-induced longevity in C. elegans. Nature 447:545-549

21. Hasegawa K, Miwa J (2010) Genetic and cellular characterization of Caenorhabditis elegans mutants abnormal in the regulation of many phase II enzymes. PLoS One 5:e11194

22. Choe KP, Przybysz AJ, Strange K (2009) The WD40 repeat protein WDR-23 functions with the CUL4/DDB1 ubiquitin ligase to regulate nuclear abundance and activity of SKN-1 in Caenorhabditis elegans. Mol Cell Biol 29:2704-2715

23. Mohler J, Vani K, Leung S, Epstein A (1991) Segmentally restricted, cephalic expression of a leucine zipper gene during Drosophila embryogenesis. Mech Dev 34:3-9

24. Andrews NC, Erdjument-Bromage H, Davidson MB, Tempst P, Orkin SH (1993) Erythroid transcription factor NF-E2 is a haematopoietic-specific basic-leucine zipper protein. Nature 362:722-728

25. Pitoniak A, Bohmann D (2015) Mechanisms and functions of Nrf2 signaling in Drosophila. Free Radic Biol Med 88:302-313

26. McGinnis N, Ragnhildstveit E, Veraksa A, McGinnis W (1998) A cap ' $n$ ' collar protein isoform contains a selective Hox repressor function. Development 125:4553-4564

27. Perrimon N, Lanjuin A, Arnold C, Noll E (1996) Zygotic lethal mutations with maternal effect phenotypes in Drosophila melanogaster. II. Loci on the second and third chromosomes identified by p-element-induced mutations. Genetics 144:1681-1692

28. Deng H, Kerppola TK (2014) Visualization of the Drosophila dKeap1-Cncc interaction on chromatin illumines cooperative, xenobiotic-specific gene activation. Development 141:3277-3288

29. Sykiotis GP, Bohmann D (2008) Keap1/Nrf2 signaling regulates oxidative stress tolerance and lifespan in Drosophila. Dev Cell $14: 76-85$

30. Blank V (2008) Small Maf proteins in mammalian gene control: mere dimerization partners or dynamic transcriptional regulators? J Mol Biol 376:913-925

31. Veraksa A, McGinnis N, Li X, Mohler J, McGinnis W (2000) Cap ' $n$ ' collar B cooperates with a small Maf subunit to specify pharyngeal development and suppress deformed homeotic function in the Drosophila head. Development. 127:4023-4037

32. Misra JR, Lam G, Tmitsmmel CS (2013) Constitutive activation of the Nrf2/Keap1 pathway in insecticide-resistant strains of Drosophila. Insect Biochem Mol Biol 43:1116-1124

33. Misra JR, Horner MA, Lam G, Thummel CS (2011) Transcriptional regulation of xenobiotic detoxification in Drosophila. Genes Dev 25:1796-1806

34. Daborn PJ, Yen JL, Bogwitz MR, Le Goff G, Feil E, Jeffers S, Tijet N, Perry T, Heckel D, Batterham P, Feyereisen R, Wilson TG, ffrench-Constant RH (2002) A single p450 allele associated with insecticide resistance in Drosophila. Science 297: 2253-2256

35. Daborn PJ, Lumb C, Boey A, Wong W, Ffrench-Constant RH, Batterham P (2007) Evaluating the insecticide resistance potential of eight Drosophila melanogaster cytochrome p450 genes by transgenic over-expression. Insect Biochem Mol Biol 37:512-519

36. Jones RM, Desai C, Darby TM, Luo L, Wolfarth AA, Scharer CD, Ardita CS, Reedy AR, Keebaugh ES, Neish AS (2015) Lactobacilli modulate epithelial cytoprotection through the Nrf2 pathway. Cell Rep 12:1217-1225

37. Steinbaugh MJ, Narasimhan SD, Robida-Stubbs S, Moronetti Mazzeo LE, Dreyfuss JM, Hourihan JM, Raghavan P, Operana TN, Esmaillie R, Blackwell TK (2015) Lipid-mediated regulation of SKN-1/Nrf in response to germ cell absence. elife 4:e07836

38. Pang S, Lynn DA, Lo JY, Paek J, Curran SP (2014) SKN-1 and Nrf2 couples proline catabolism with lipid metabolism during nutrient deprivation. Nat Commun 5:5048

39. Seydoux G, Fire A (1994) Soma-germline asymmetry in the distributions of embryonic RNAs in Caenorhabditis elegans. Development 120:2823-2834

40. Page BD, Diede SJ, Tenlen JR, Ferguson EL (2007) EEL-1, a Hect e3 ubiquitin ligase, controls asymmetry and persistence of the skn-1 transcription factor in the early $C$. elegans embryo. Development 134:2303-2314

41. Bowerman B, Eaton BA, Priess JR (1992) Skn-1, a maternally expressed gene required to specify the fate of ventral blastomeres in the early C. elegans embryo. Cell 68:1061-1075

42. Bowerman B, Draper BW, Mello CC, Priess JR (1993) The maternal gene skn-1 encodes a protein that is distributed unequally in early C. elegans embryos. Cell 74:443-452

43. Maduro MF, Meneghini MD, Bowerman B, Broitman-Maduro G, Rothman JH (2001) Restriction of mesendoderm to a single blastomere by the combined action of SKN-1 and a GSK-3beta homolog is mediated by MED- 1 and -2 in C. elegans. Mol Cell $7: 475-485$

44. Coroian C, Broitman-Maduro G, Maduro MF (2006) Med-type GATA factors and the evolution of mesendoderm specification in nematodes. Dev Biol 289:444-455

45. Broitman-Maduro G, Lin KT, Hung WW, Maduro MF (2006) Specification of the $C$. elegans MS blastomere by the T-box factor TBX-35. Development 133:3097-3106

46. Broitman-Maduro G, Owraghi M, Hung WW, Kuntz S, Sternberg PW, Maduro MF (2009) The NK-2 class homeodomain factor CEH-51 and the T-box factor TBX-35 have overlapping function in C. elegans mesoderm development. Development 136:2735-2746

47. Huang S, Shetty P, Robertson SM, Lin R (2007) Binary cell fate specification during $C$. elegans embryogenesis driven by reiterated reciprocal asymmetry of TCF POP-1 and its coactivator beta-catenin SYS-1. Development 134:2685-2695

48. Phillips BT, Kidd AR 3rd, King R, Hardin J, Kimble J (2007) Reciprocal asymmetry of SYS-1/beta-catenin and POP-1/TCF controls asymmetric divisions in Caenorhabditis elegans. Proc Natl Acad Sci USA 104:3231-3236

49. Fukushige T, Hendzel MJ, Bazett-Jones DP, McGhee JD (1999) Direct visualization of the elt-2 gut-specific GATA factor binding to a target promoter inside the living Caenorhabditis elegans embryo. Proc Natl Acad Sci USA 96:11883-11888

50. Maduro MF, Kasmir JJ, Zhu J, Rothman JH (2005) The Wnt effector POP-1 and the PAL-1/Caudal homeoprotein collaborate with SKN-1 to activate $C$. elegans endoderm development. Dev Biol 285:510-523

51. McGhee JD, Fukushige T, Krause MW, Minnema SE, Goszczynski B, Gaudet J, Kohara Y, Bossinger O, Zhao Y, Khattra J, Hirst M, Jones SJ, Marra MA, Ruzanov P, Warner A, Zapf R, Moerman DG, Kalb JM (2009) ELT-2 is the predominant transcription factor controlling differentiation and function of the $C$. elegans intestine, from embryo to adult. Dev Biol 327:551-565 
52. Guichet A, Peri F, Roth S (2001) Stable anterior anchoring of the oocyte nucleus is required to establish dorsoventral polarity of the Drosophila egg. Dev Biol 237:93-106

53. Rogers B, Peterson M, Kaufman T (2002) The development and evolution of insect mouthparts as revealed by the expression patterns of gnathocephalic genes. Evol Dev 4:96-110

54. Seecoomar M, Agarwal S, Vani K, Yang G, Mohler J (2000) Knot is required for the hypopharyngeal lobe and its derivatives in the Drosophila embryo. Mech Dev 91:209-215

55. Vervoort M, Crozatier M, Valle D, Vincent A (1999) The COE transcription factor Collier is a mediator of short-range Hedgehog-induced patterning of the Drosophila wing. Curr Biol 9:632-639

56. Mohler J (1993) Genetic regulation of cnc expression in the pharnygeal primordia of Drosophila blastoderm embryos. Rouxs Arch Dev Biol 202:214-223

57. Mohler J, Mahaffey J, Deutsch E, Vani K (1995) Control of Drosophila head segment identity by the bZIP homeotic gene cnc. Development 121:237-247

58. Ntini E, Wimmer EA (2011) Second order regulator Collier directly controls intercalary-specific segment polarity gene expression. Dev Biol 360:403-414

59. Deng H (2014) Multiple roles of Nrf2-Keap1 signaling: regulation of development and xenobiotic response using distinct mechanisms. Fly 8:7-12

60. Deng H, Kerppola TK (2013) Regulation of Drosophila metamorphosis by xenobiotic response regulators. PLoS Genet 9:e1003263

61. Hochmuth CE, Biteau B, Bohmann D, Jasper H (2011) Redox regulation by Keap1 and Nrf2 controls intestinal stem cell proliferation in Drosophila. Cell Stem Cell 8:188-199

62. Chan JY, Kwong M, Lu R, Chang J, Wang B, Yen TS, Kan YW (1998) Targeted disruption of the ubiquitous CNC-bZIP transcription factor, Nrf-1, results in anemia and embryonic lethality in mice. EMBO J 17:1779-1787

63. Chan K, Lu R, Chang JC, Kan YW (1996) NRF2, a member of the NFE2 family of transcription factors, is not essential for murine erythropoiesis, growth, and development. Proc Natl Acad Sci USA 93:13943-13948

64. Derjuga A, Gourley TS, Holm TM, Heng HH, Shivdasani RA, Ahmed R, Andrews NC, Blank V (2004) Complexity of CNC transcription factors as revealed by gene targeting of the Nrf3 locus. Mol Cell Biol 24:3286-3294

65. Leung L, Kwong M, Hou S, Lee C, Chan JY (2003) Deficiency of the Nrf1 and Nrf2 transcription factors results in early embryonic lethality and severe oxidative stress. J Biol Chem 278:48021-48029

66. Alam J, Stewart D, Touchard C, Boinapally S, Choi AM, Cook JL (1999) Nrf2, a Cap'n'Collar transcription factor, regulates induction of the heme oxygenase-1 gene. J Biol Chem 274:26071-26078

67. Loboda A, Jazwa A, Grochot-Przeczek A, Rutkowski AJ, Cisowski J, Agarwal A, Jozkowicz A, Dulak J (2008) Heme oxygenase-1 and the vascular bed: from molecular mechanisms to therapeutic opportunities. Antioxid Redox Signal 10:1767-1812

68. Balla G, Jacob HS, Balla J, Rosenberg M, Nath K, Apple F, Eaton JW, Vercellotti GM (1992) Ferritin: a cytoprotective antioxidant stratagem of endothelium. J Biol Chem 267:18148-18153

69. Cheng HT, Yen CJ, Chang CC, Huang KT, Chen KH, Zhang RY, Lee PY, Miaw SC, Huang JW, Chiang CK, Wu KD, Hung KY (2015) Ferritin heavy chain mediates the protective effect of heme oxygenase- 1 against oxidative stress. Biochim Biophys Acta 1850:2506-2517

70. Loboda A, Jozkowicz A, Dulak J (2015) HO-1/CO system in tumor growth, angiogenesis and metabolism-targeting ho-1 as an anti-tumor therapy. Vascul Pharmacol 74:11-22
71. Ryter SW, Choi AM (2016) Targeting heme oxygenase-1 and carbon monoxide for therapeutic modulation of inflammation. Transl Res 167:7-34

72. Poss KD, Tonegawa S (1997) Reduced stress defense in heme oxygenase 1-deficient cells. Proc Natl Acad Sci USA 94:10925-10930

73. Poss KD, Tonegawa S (1997) Heme oxygenase 1 is required for mammalian iron reutilization. Proc Natl Acad Sci USA 94:10919-10924

74. Yet SF, Perrella MA, Layne MD, Hsieh CM, Maemura K, Kobzik L, Wiesel P, Christou H, Kourembanas S, Lee ME (1999) Hypoxia induces severe right ventricular dilatation and infarction in heme oxygenase-1 null mice. J Clin Invest 103:R23-R29

75. Yachie A, Niida Y, Wada T, Igarashi N, Kaneda H, Toma T, Ohta K, Kasahara Y, Koizumi S (1999) Oxidative stress causes enhanced endothelial cell injury in human heme oxygenase-1 deficiency. J Clin Invest 103:129-135

76. Radhakrishnan N, Yadav SP, Sachdeva A, Pruthi PK, Sawhney S, Piplani T, Wada T, Yachie A (2011) Human heme oxygenase-1 deficiency presenting with hemolysis, nephritis, and asplenia. J Pediatr Hematol Oncol 33:74-78

77. Taha H, Skrzypek K, Guevara I, Nigisch A, Mustafa S, GrochotPrzeczek A, Ferdek P, Was H, Kotlinowski J, Kozakowska M, Balcerczyk A, Muchova L, Vitek L, Weigel G, Dulak J, Jozkowicz A (2010) Role of heme oxygenase-1 in human endothelial cells: lesson from the promoter allelic variants. Arterioscler Thromb Vasc Biol 30:1634-1641

78. Pechlaner R, Willeit P, Summerer M, Santer P, Egger G, Kronenberg F, Demetz E, Weiss G, Tsimikas S, Witztum JL, Willeit K, Iglseder B, Paulweber B, Kedenko L, Haun M, Meisinger C, Gieger C, Muller-Nurasyid M, Peters A, Willeit J, Kiechl S (2015) Heme oxygenase-1 gene promoter microsatellite polymorphism is associated with progressive atherosclerosis and incident cardiovascular disease. Arterioscler Thromb Vasc Biol 35:229-236

79. Qiao H, Sai X, Gai L, Huang G, Chen X, Tu X, Ding Z (2014) Association between heme oxygenase 1 gene promoter polymorphisms and susceptibility to coronary artery disease: a huge review and meta-analysis. Am $J$ Epidemiol 179:1039-1048

80. Chang KW, Lee TC, Yeh WI, Chung MY, Liu CJ, Chi LY, Lin SC (2004) Polymorphism in heme oxygenase-1 (HO-1) promoter is related to the risk of oral squamous cell carcinoma occurring on male areca chewers. Br J Cancer 91:1551-1555

81. Lo SS, Lin SC, Wu CW, Chen JH, Yeh WI, Chung MY, Lui WY (2007) Heme oxygenase-1 gene promoter polymorphism is associated with risk of gastric adenocarcinoma and lymphovascular tumor invasion. Ann Surg Oncol 14:2250-2256

82. Kikuchi A, Yamaya M, Suzuki S, Yasuda H, Kubo H, Nakayama K, Handa M, Sasaki T, Shibahara S, Sekizawa K, Sasaki H (2005) Association of susceptibility to the development of lung adenocarcinoma with the heme oxygenase-1 gene promoter polymorphism. Hum Genet 116:354-360

83. Vashist YK, Uzungolu G, Kutup A, Gebauer F, Koenig A, Deutsch L, Zehler O, Busch P, Kalinin V, Izbicki JR, Yekebas EF (2011) Heme oxygenase-1 germ line gtn promoter polymorphism is an independent prognosticator of tumor recurrence and survival in pancreatic cancer. J Surg Oncol 104:305-311

84. Okamoto I, Krogler J, Endler G, Kaufmann S, Mustafa S, Exner M, Mannhalter C, Wagner O, Pehamberger H (2006) A microsatellite polymorphism in the heme oxygenase-1 gene promoter is associated with risk for melanoma. Int $\mathrm{J}$ Cancer 119:1312-1315

85. Zhang L, Song FF, Huang YB, Zheng H, Song FJ, Chen KX (2014) Association between the (GT) $n$ polymorphism of the HO- 
1 gene promoter region and cancer risk: a meta-analysis. Asian Pac J Cancer Prev 15:4617-4622

86. Wu MM, Lee CH, Hsu LI, Cheng WF, Lee TC, Wang YH, Chiou HY, Chen CJ (2016) Effect of heme oxygenase-1 gene promoter polymorphism on cancer risk by histological subtype: a prospective study in arseniasis-endemic areas in Taiwan. Int $\mathbf{J}$ Cancer 138:1875-1886

87. Kimpara T, Takeda A, Watanabe K, Itoyama Y, Ikawa S, Watanabe M, Arai H, Sasaki H, Higuchi S, Okita N, Takase S, Saito H, Takahashi K, Shibahara S (1997) Microsatellite polymorphism in the human heme oxygenase-1 gene promoter and its application in association studies with Alzheimer and Parkinson disease. Hum Genet 100:145-147

88. Funke C, Tomiuk J, Riess O, Berg D, Soehn AS (2009) Genetic analysis of heme oxygenase-1 (ho-1) in German Parkinson's disease patients. J Neural Transm 116:853-859

89. Infante J, Garcia-Gorostiaga I, Sanchez-Juan P, Sierra M, Martin-Gurpegui JL, Terrazas J, Mateo I, Rodriguez-Rodriguez E, Berciano J, Combarros O (2010) Synergistic effect of two oxidative stress-related genes (heme oxygenase-1 and GSK3 $\beta$ ) on the risk of Parkinson's disease. Eur J Neurol 17:760-762

90. Watanabe S, Akagi R, Mori M, Tsuchiya T, Sassa S (2004) Marked developmental changes in heme oxygenase-1 (HO-1) expression in the mouse placenta: correlation between HO-1 expression and placental development. Placenta 25:387-395

91. Ihara N, Akagi R, Ejiri K, Kudo T, Furuyama K, Fujita H (1998) Developmental changes of gene expression in heme metabolic enzymes in rat placenta. FEBS Lett 439:163-167

92. Zenclussen ML, Linzke N, Schumacher A, Fest S, Meyer N, Casalis PA, Zenclussen AC (2014) Heme oxygenase-1 is critically involved in placentation, spiral artery remodeling, and blood pressure regulation during murine pregnancy. Front Pharmacol 5:291

93. Zhao H, Wong RJ, Kalish FS, Nayak NR, Stevenson DK (2009) Effect of heme oxygenase-1 deficiency on placental development. Placenta 30:861-868

94. Zenclussen ML, Anegon I, Bertoja AZ, Chauveau C, Vogt K, Gerlof K, Sollwedel A, Volk HD, Ritter T, Zenclussen AC (2006) Over-expression of heme oxygenase-1 by adenoviral gene transfer improves pregnancy outcome in a murine model of abortion. J Reprod Immunol 69:35-52

95. Kreiser D, Nguyen X, Wong R, Seidman D, Stevenson D, Quan S, Abraham N, Dennery PA (2002) Heme oxygenase-1 modulates fetal growth in the rat. Lab Invest 82:687-692

96. Lin TC, Yen JM, Gong KB, Hsu TT, Chen LR (2003) IGF-1/ IGFP-1 increases blastocyst formation and total blastocyst cell number in mouse embryo culture and facilitates the establishment of a stem-cell line. BMC Cell Biol 4:14

97. Lin CY, Peng CY, Huang TT, Wu ML, Lai YL, Peng DH, Chen PF, Chen HF, Yen BL, Wu KK, Yet SF (2012) Exacerbation of oxidative stress-induced cell death and differentiation in induced pluripotent stem cells lacking heme oxygenase-1. Stem Cells Dev 21:1675-1687

98. Zhang X, Sato M, Sasahara M, Migita CT, Yoshida T (2004) Unique features of recombinant heme oxygenase of Drosophila melanogaster compared with those of other heme oxygenases studied. Eur J Biochem 271:1713-1724

99. Cui L, Yoshioka Y, Suyari O, Kohno Y, Zhang X, Adachi Y, Ikehara S, Yoshida T, Yamaguchi M, Taketani S (2008) Relevant expression of Drosophila heme oxygenase is necessary for the normal development of insect tissues. Biochem Biophys Res Commun 377:1156-1161

100. Ceriani MF, Hogenesch JB, Yanovsky M, Panda S, Straume M, Kay SA (2002) Genome-wide expression analysis in Drosophila reveals genes controlling circadian behavior. J Neurosci 22:9305-9319
101. Troxler RF, Brown AS, Brown SB (1979) Bile pigment synthesis in plants. Mechanism of 180 incorporation into phycocyanobilin in the unicellular rhodophyte. Cyanidium caldarium. J Biol Chem 254:3411-3418

102. Beale SI, Cornejo J (1984) Enzymatic heme oxygenase activity in soluble extracts of the unicellular red alga, Cyanidium caldarium. Arch Biochem Biophys 235:371-384

103. Muramoto T, Kohchi T, Yokota A, Hwang I, Goodman HM (1999) The arabidopsis photomorphogenic mutant hy1 is deficient in phytochrome chromophore biosynthesis as a result of a mutation in a plastid heme oxygenase. Plant Cell $11: 335-348$

104. Emborg TJ, Walker JM, Noh B, Vierstra RD (2006) Multiple heme oxygenase family members contribute to the biosynthesis of the phytochrome chromophore in Arabidopsis. Plant Physiol 140:856-868

105. Matsumoto F, Obayashi T, Sasaki-Sekimoto Y, Ohta H, Takamiya K, Masuda T (2004) Gene expression profiling of the tetrapyrrole metabolic pathway in arabidopsis with a mini-array system. Plant Physiol 135:2379-2391

106. Balestrasse KB, Noriega GO, Batlle A, Tomaro ML (2005) Involvement of heme oxygenase as antioxidant defense in soybean nodules. Free Radic Res 39:145-151

107. Frankenberg-Dinkel N (2004) Bacterial heme oxygenases. Antioxid Redox Signal 6:825-834

108. Wilks A, Schmitt MP (1998) Expression and characterization of a heme oxygenase $(\mathrm{Hmu} \mathrm{O})$ from corynebacterium diphtheriae. Iron acquisition requires oxidative cleavage of the heme macrocycle. J Biol Chem 273:837-841

109. Zhu W, Wilks A, Stojiljkovic I (2000) Degradation of heme in Gram-negative bacteria: the product of the hemO gene of Neisseriae is a heme oxygenase. J Bacteriol 182:6783-6790

110. Lewis KN, Mele J, Hayes JD, Buffenstein R (2010) Nrf2, a guardian of healthspan and gatekeeper of species longevity. Integr Comp Biol 50:829-843

111. Rahman MM, Sykiotis GP, Nishimura M, Bodmer R, Bohmann D (2013) Declining signal dependence of Nrf2-MafS-regulated gene expression correlates with aging phenotypes. Aging Cell 12:554-562

112. Sohal RS, Weindruch R (1996) Oxidative stress, caloric restriction, and aging. Science 273:59-63

113. Pearson KJ, Lewis KN, Price NL, Chang JW, Perez E, Cascajo MV, Tamashiro KL, Poosala S, Csiszar A, Ungvari Z, Kensler TW, Yamamoto M, Egan JM, Longo DL, Ingram DK, Navas P, de Cabo R (2008) Nrf2 mediates cancer protection but not prolongevity induced by caloric restriction. Proc Natl Acad Sci USA 105:2325-2330

114. Smith-Vikos T, de Lencastre A, Inukai S, Shlomchik M, Holtrup B, Slack FJ (2014) Micrornas mediate dietary-restriction-induced longevity through PHA-4/FOXA and SKN-1/Nrf transcription factors. Curr Biol 24:2238-2246

115. de Lencastre A, Pincus Z, Zhou K, Kato M, Lee SS, Slack FJ (2010) MicroRNAs both promote and antagonize longevity in $C$. elegans. Curr Biol 20:2159-2168

116. Tullet JM, Hertweck M, An JH, Baker J, Hwang JY, Liu S, Oliveira RP, Baumeister R, Blackwell TK (2008) Direct inhibition of the longevity-promoting factor SKN-1 by insulin-like signaling in C. elegans. Cell 132:1025-1038

117. Ewald CY, Landis JN, Porter Abate J, Murphy CT, Blackwell TK (2015) Dauer-independent insulin/IGF-1-signalling implicates collagen remodelling in longevity. Nature 519:97-101

118. Olahova M, Veal EA (2015) A peroxiredoxin, PRDX-2, is required for insulin secretion and insulin/IIs-dependent regulation of stress resistance and longevity. Aging Cell 14:558-568

119. Seo HW, Cheon SM, Lee MH, Kim HJ, Jeon H, Cha DS (2015) Catalpol modulates lifespan via DAF-16/FOXO and SKN-1/ 
Nrf2 activation in Caenorhabditis elegans. Evid Based Complement Alternat Med 2015:524878

120. Robida-Stubbs S, Glover-Cutter K, Lamming DW, Mizunuma M, Narasimhan SD, Neumann-Haefelin E, Sabatini DM, Blackwell TK (2012) TOR signaling and rapamycin influence longevity by regulating SKN-1/Nrf and DAF-16/FoxO. Cell Metab 15:713-724

121. Mizunuma M, Neumann-Haefelin E, Moroz N, Li Y, Blackwell TK (2014) mTORC2-SGK-1 acts in two environmentally responsive pathways with opposing effects on longevity. Aging Cell 13:869-878

122. Palikaras K, Lionaki E, Tavernarakis N (2015) Coupling mitogenesis and mitophagy for longevity. Autophagy 11:1428-1430

123. Palikaras K, Lionaki E, Tavernarakis N (2015) Coordination of mitophagy and mitochondrial biogenesis during ageing in $C$. elegans. Nature 521:525-528

124. Itoh K, Ye P, Matsumiya T, Tanji K, Ozaki T (2015) Emerging functional cross-talk between the keap1-nrf2 system and mitochondria. J Clin Biochem Nutr 56:91-97

125. Amador-Noguez D, Yagi K, Venable S, Darlington G (2004) Gene expression profile of long-lived ames dwarf mice and little mice. Aging Cell 3:423-441

126. Lewis KN, Wason E, Edrey YH, Kristan DM, Nevo E, Buffenstein R (2015) Regulation of nrf2 signaling and longevity in naturally long-lived rodents. Proc Natl Acad Sci USA 112:3722-3727

127. Tsakiri EN, Sykiotis GP, Papassideri IS, Gorgoulis VG, Bohmann D, Trougakos IP (2013) Differential regulation of proteasome functionality in reproductive vs. somatic tissues of Drosophila during aging or oxidative stress. FASEB J 27:2407-2420

128. Chondrogianni N, Stratford FL, Trougakos IP, Friguet B, Rivett AJ, Gonos ES (2003) Central role of the proteasome in senescence and survival of human fibroblasts: induction of a senescence-like phenotype upon its inhibition and resistance to stress upon its activation. J Biol Chem 278:28026-28037

129. Pickering AM, Davies KJ (2012) Degradation of damaged proteins: the main function of the $20 \mathrm{~S}$ proteasome. Prog Mol Biol Transl Sci 109:227-248

130. Navon A, Ciechanover A (2009) The 26S proteasome: from basic mechanisms to drug targeting. J Biol Chem 284:33713-33718

131. Grimberg KB, Beskow A, Lundin D, Davis MM, Young P (2011) Basic leucine zipper protein Cnc-C is a substrate and transcriptional regulator of the Drosophila 26S proteasome. Mol Cell Biol 31:897-909

132. Lundgren J, Masson P, Mirzaei Z, Young P (2005) Identification and characterization of a Drosophila proteasome regulatory network. Mol Cell Biol 25:4662-4675

133. Pickering AM, Staab TA, Tower J, Sieburth D, Davies KJ (2013) A conserved role for the $20 \mathrm{~S}$ proteasome and Nrf2 transcription factor in oxidative stress adaptation in mammals, Caenorhabditis elegans and Drosophila melanogaster. J Exp Biol 216:543-553

134. Tsakiri EN, Sykiotis GP, Papassideri IS, Terpos E, Dimopoulos MA, Gorgoulis VG, Bohmann D, Trougakos IP (2013) Proteasome dysfunction in Drosophila signals to an Nrf2-dependent regulatory circuit aiming to restore proteostasis and prevent premature aging. Aging Cell 12:802-813

135. Wang J, Robida-Stubbs S, Tullet JM, Rual JF, Vidal M, Blackwell TK (2010) RNAi screening implicates a SKN-1-dependent transcriptional response in stress resistance and longevity deriving from translation inhibition. PLoS Genet 6:e1001048

136. Chondrogianni N, Georgila K, Kourtis N, Tavernarakis N, Gonos ES (2015) 20S proteasome activation promotes life span extension and resistance to proteotoxicity in Caenorhabditis elegans. FASEB J 29:611-622

137. Kwak MK, Wakabayashi N, Greenlaw JL, Yamamoto M, Kensler TW (2003) Antioxidants enhance mammalian proteasome expression through the Keap1-Nrf2 signaling pathway. Mol Cell Biol 23:8786-8794

138. Suh JH, Shenvi SV, Dixon BM, Liu H, Jaiswal AK, Liu RM, Hagen TM (2004) Decline in transcriptional activity of Nrf2 causes age-related loss of glutathione synthesis, which is reversible with lipoic acid. Proc Natl Acad Sci USA 101:3381-3386

139. Duan W, Zhang R, Guo Y, Jiang Y, Huang Y, Jiang H, Li C (2009) Nrf2 activity is lost in the spinal cord and its astrocytes of aged mice. In Vitro Cell Dev Biol Anim 45:388-397

140. Suzuki M, Betsuyaku T, Ito Y, Nagai K, Nasuhara Y, Kaga K, Kondo S, Nishimura M (2008) Down-regulated NF-E2-related factor 2 in pulmonary macrophages of aged smokers and patients with chronic obstructive pulmonary disease. Am J Respir Cell Mol Biol 39:673-682

141. Kraft AD, Johnson DA, Johnson JA (2004) Nuclear factor E2related factor 2-dependent antioxidant response element activation by tert-butylhydroquinone and sulforaphane occurring preferentially in astrocytes conditions neurons against oxidative insult. J Neurosci 24:1101-1112

142. Johnson JA, Johnson DA, Kraft AD, Calkins MJ, Jakel RJ, Vargas MR, Chen PC (2008) The Nrf2-ARE pathway: an indicator and modulator of oxidative stress in neurodegeneration. Ann N Y Acad Sci 1147:61-69

143. Calkins MJ, Jakel RJ, Johnson DA, Chan K, Kan YW, Johnson JA (2005) Protection from mitochondrial complex II inhibition in vitro and in vivo by Nrf2-mediated transcription. Proc Natl Acad Sci USA 102:244-249

144. Jakel RJ, Townsend JA, Kraft AD, Johnson JA (2007) Nrf2mediated protection against 6-hydroxydopamine. Brain Res 1144:192-201

145. Burton NC, Kensler TW, Guilarte TR (2006) In vivo modulation of the parkinsonian phenotype by nrf2. Neurotoxicology 27:1094-1100

146. Innamorato NG, Jazwa A, Rojo AI, Garcia C, Fernandez-Ruiz J, Grochot-Przeczek A, Stachurska A, Jozkowicz A, Dulak J, Cuadrado A (2010) Different susceptibility to the Parkinson's toxin MPTP in mice lacking the redox master regulator Nrf2 or its target gene heme oxygenase-1. PLoS One 5:e11838

147. Jazwa A, Rojo AI, Innamorato NG, Hesse M, Fernandez-Ruiz J, Cuadrado A (2011) Pharmacological targeting of the transcription factor Nrf2 at the basal ganglia provides disease modifying therapy for experimental parkinsonism. Antioxid Redox Signal 14:2347-2360

148. Hung SY, Liou HC, Kang KH, Wu RM, Wen CC, Fu WM (2008) Overexpression of heme oxygenase-1 protects dopaminergic neurons against 1-methyl-4-phenylpyridiniuminduced neurotoxicity. Mol Pharmacol 74:1564-1575

149. Trinh K, Moore K, Wes PD, Muchowski PJ, Dey J, Andrews L, Pallanck LJ (2008) Induction of the phase II detoxification pathway suppresses neuron loss in Drosophila models of Parkinson's disease. J Neurosci 28:465-472

150. Trinh K, Andrews L, Krause J, Hanak T, Lee D, Gelb M, Pallanck L (2010) Decaffeinated coffee and nicotine-free tobacco provide neuroprotection in Drosophila models of Parkinson's disease through an NRF2-dependent mechanism. J Neurosci 30:5525-5532

151. Barone MC, Sykiotis GP, Bohmann D (2011) Genetic activation of Nrf2 signaling is sufficient to ameliorate neurodegenerative phenotypes in a Drosophila model of Parkinson's disease. Dis Model Mech 4:701-707 
152. Wang B, Liu Q, Shan H, Xia C, Liu Z (2015) Nrf2 inducer and Cncc overexpression attenuates neurodegeneration due to $\alpha$ synuclein in Drosophila. Biochem Cell Biol 93:351-358

153. Wang Y, Santa-Cruz K, DeCarli C, Johnson JA (2000) $\mathrm{NAD}(\mathrm{P}) \mathrm{H}$ :quinone oxidoreductase activity is increased in hippocampal pyramidal neurons of patients with Alzheimer's disease. Neurobiol Aging 21:525-531

154. Tanji K, Maruyama A, Odagiri S, Mori F, Itoh K, Kakita A, Takahashi H, Wakabayashi K (2013) Keap1 is localized in neuronal and glial cytoplasmic inclusions in various neurodegenerative diseases. J Neuropathol Exp Neurol 72:18-28

155. Schipper HM, Bennett DA, Liberman A, Bienias JL, Schneider JA, Kelly J, Arvanitakis Z (2006) Glial heme oxygenase-1 expression in Alzheimer disease and mild cognitive impairment. Neurobiol Aging 27:252-261

156. Gupta A, Lacoste B, Pistell PJ, Ingram DK, Hamel E, AlaouiJamali MA, Szarek WA, Vlahakis JZ, Jie S, Song W, Schipper HM (2014) Neurotherapeutic effects of novel HO-1 inhibitors in vitro and in a transgenic mouse model of Alzheimer's disease. J Neurochem 131:778-790

157. Ramsey CP, Glass CA, Montgomery MB, Lindl KA, Ritson GP, Chia LA, Hamilton RL, Chu CT, Jordan-Sciutto KL (2007) Expression of nrf2 in neurodegenerative diseases. J Neuropathol Exp Neurol 66:75-85

158. Yamazaki H, Tanji K, Wakabayashi K, Matsuura S, Itoh K (2015) Role of the Keap1/Nrf2 pathway in neurodegenerative diseases. Pathol Int 65:210-219

159. Arnold P, Mojumder D, Detoledo J, Lucius R, Wilms H (2014) Pathophysiological processes in multiple sclerosis: focus on nuclear factor erythroid-2-related factor 2 and emerging pathways. Clin Pharmacol 6:35-42

160. Cada DJ, Levien TL, Baker DE (2013) Dimethyl fumarate. Hosp Pharm 48:668-679

161. Bomprezzi R (2015) Dimethyl fumarate in the treatment of relapsing-remitting multiple sclerosis: an overview. Ther Adv Neurol Disord 8:20-30

162. Nicholas JA, Boster AL, Imitola J, O'Connell C, Racke MK (2014) Design of oral agents for the management of multiple sclerosis: benefit and risk assessment for dimethyl fumarate. Drug Des Devel Ther 8:897-908

163. Linker RA, Lee DH, Ryan S, van Dam AM, Conrad R, Bista P, Zeng W, Hronowsky X, Buko A, Chollate S, Ellrichmann G, Brück W, Dawson K, Goelz S, Wiese S, Scannevin RH, Lukashev M, Gold R (2011) Fumaric acid esters exert neuroprotective effects in neuroinflammation via activation of the Nrf2 antioxidant pathway. Brain 134:678-692

164. Lijnen R, Otters E, Balak D, Thio B (2016) Long-term safety and effectiveness of high-dose dimethylfumarate in the treatment of moderate to severe psoriasis: a prospective singleblinded follow-up study. J Dermatolog Treat 27:31-36

165. Gill AJ, Kolson DL (2013) Dimethyl fumarate modulation of immune and antioxidant responses: application to HIV therapy. Crit Rev Immunol 33:307-359

166. Karkkainen V, Pomeshchik Y, Savchenko E, Dhungana H, Kurronen A, Lehtonen S, Naumenko N, Tavi P, Levonen AL, Yamamoto M, Malm T, Magga J, Kanninen KM, Koistinaho J (2014) Nrf2 regulates neurogenesis and protects neural progenitor cells against A $\beta$ toxicity. Stem Cells 32:1904-1916

167. Joshi G, Gan KA, Johnson DA, Johnson JA (2015) Increased Alzheimer's disease-like pathology in the APP/PS $\triangle E$ 9 mouse model lacking Nrf2 through modulation of autophagy. Neurobiol Aging 36:664-679

168. Lau A, Wang XJ, Zhao F, Villeneuve NF, Wu T, Jiang T, Sun Z, White E, Zhang DD (2010) A noncanonical mechanism of Nrf2 activation by autophagy deficiency: direct interaction between Keap1 and p62. Mol Cell Biol 30:3275-3285
169. Komatsu M, Kurokawa H, Waguri S, Taguchi K, Kobayashi A, Ichimura Y, Sou YS, Ueno I, Sakamoto A, Tong KI, Kim M, Nishito $\mathrm{Y}$, Iemura $\mathrm{S}$, Natsume $\mathrm{T}$, Ueno $\mathrm{T}$, Kominami $\mathrm{E}$, Motohashi H, Tanaka K, Yamamoto M (2010) The selective autophagy substrate p62 activates the stress responsive transcription factor Nrf2 through inactivation of Keap1. Nat Cell Biol 12:213-223

170. Ichimura Y, Waguri S, Sou YS, Kageyama S, Hasegawa J, Ishimura R, Saito T, Yang Y, Kouno T, Fukutomi T, Hoshii T, Hirao A, Takagi K, Mizushima T, Motohashi H, Lee MS, Yoshimori T, Tanaka K, Yamamoto M, Komatsu M (2013) Phosphorylation of p62 activates the Keap1-Nrf2 pathway during selective autophagy. Mol Cell 51:618-631

171. Jain A, Lamark T, Sjottem E, Larsen KB, Awuh JA, Overvatn A, McMahon M, Hayes JD, Johansen T (2010) p62/SQSTM1 is a target gene for transcription factor Nrf2 and creates a positive feedback loop by inducing antioxidant response element-driven gene transcription. J Biol Chem 285:22576-22591

172. Kageyama S, Sou YS, Uemura T, Kametaka S, Saito T, Ishimura R, Kouno T, Bedford L, Mayer RJ, Lee MS, Yamamoto M, Waguri S, Tanaka K, Komatsu M (2014) Proteasome dysfunction activates autophagy and the Keap1-Nrf2 pathway. J Biol Chem 289:24944-24955

173. Zhao Z, Chen Y, Wang J, Sternberg P, Freeman ML, Grossniklaus HE, Cai J (2011) Age-related retinopathy in Nrf2deficient mice. PLoS One 6:e19456

174. Sliwinski T, Kolodziejska U, Szaflik JP, Blasiak J, Szaflik J (2013) Association between the 25129a $>$ c polymorphism of the nuclear respiratory factor 2 gene and age-related macular degeneration. Klin Oczna 115:96-102

175. Synowiec E, Szaflik J, Chmielewska M, Wozniak K, Sklodowska A, Waszczyk M, Dorecka M, Blasiak J, Szaflik JP (2012) An association between polymorphism of the heme oxygenase- 1 and -2 genes and age-related macular degeneration. Mol Biol Rep 39:2081-2087

176. Jonasson F, Fisher DE, Eiriksdottir G, Sigurdsson S, Klein R, Launer LJ, Harris T, Gudnason V, Cotch MF (2014) Five-year incidence, progression, and risk factors for age-related macular degeneration: the age, gene/environment susceptibility study. Ophthalmology 121:1766-1772

177. Wang L, Kondo N, Cano M, Ebrahimi K, Yoshida T, Barnett BP, Biswal S, Handa JT (2014) Nrf2 signaling modulates cigarette smoke-induced complement activation in retinal pigmented epithelial cells. Free Radic Biol Med 70:155-166

178. Bertram KM, Baglole CJ, Phipps RP, Libby RT (2009) Molecular regulation of cigarette smoke induced-oxidative stress in human retinal pigment epithelial cells: implications for age-related macular degeneration. Am J Physiol Cell Physiol 297:C1200-C1210

179. Song D, Dunaief JL (2013) Retinal iron homeostasis in health and disease. Front Aging Neurosci 5:24

180. Kannan R, Hinton DR (2014) Sodium iodate induced retinal degeneration: new insights from an old model. Neural Regen Res 9:2044-2045

181. Sachdeva MM, Cano M, Handa JT (2014) Nrf2 signaling is impaired in the aging RPE given an oxidative insult. Exp Eye Res 119:111-114

182. Birch-Machin MA (2006) The role of mitochondria in ageing and carcinogenesis. Clin Exp Dermatol 31:548-552

183. Loboda A, Rojczyk-Golebiewska E, Bednarczyk-Cwynar B, Lucjusz Z, Jozkowicz A, Dulak J (2012) Targeting Nrf2-mediated gene transcription by triterpenoids and their derivatives. Biomol Ther 20:499-505

184. Kwak MK, Kensler TW (2010) Targeting nrf2 signaling for cancer chemoprevention. Toxicol Appl Pharmacol 244:66-76 
185. Iida K, Itoh K, Kumagai Y, Oyasu R, Hattori K, Kawai K, Shimazui T, Akaza H, Yamamoto M (2004) Nrf2 is essential for the chemopreventive efficacy of oltipraz against urinary bladder carcinogenesis. Cancer Res 64:6424-6431

186. Yates MS, Kwak MK, Egner PA, Groopman JD, Bodreddigari S, Sutter TR, Baumgartner KJ, Roebuck BD, Liby KT, Yore MM, Honda T, Gribble GW, Sporn MB, Kensler TW (2006) Potent protection against aflatoxin-induced tumorigenesis through induction of nrf2-regulated pathways by the triterpenoid 1-[2-cyano-3-,12-dioxooleana-1,9(11)-dien-28-oyl]imidazole. Cancer Res 66:2488-2494

187. Saw CL, Huang MT, Liu Y, Khor TO, Conney AH, Kong AN (2011) Impact of Nrf2 on UVB-induced skin inflammation/ photoprotection and photoprotective effect of sulforaphane. Mol Carcinog 50:479-486

188. Bauer AK, Hill T 3rd, Alexander CM (2013) The involvement of Nrf2 in lung cancer. Oxid Med Cell Longev. 2013:746432

189. Singh A, Misra V, Thimmulappa RK, Lee H, Ames S, Hoque MO, Herman JG, Baylin SB, Sidransky D, Gabrielson E, Brock MV, Biswal S (2006) Dysfunctional Keap1-Nrf2 interaction in non-small-cell lung cancer. PLoS Med 3:e420

190. Kim YR, Oh JE, Kim MS, Kang MR, Park SW, Han JY, Eom HS, Yoo NJ, Lee SH (2010) Oncogenic nrf2 mutations in squamous cell carcinomas of oesophagus and skin. J Pathol 220:446-451

191. Adam J, Hatipoglu E, O'Flaherty L, Ternette N, Sahgal N, Lockstone H, Baban D, Nye E, Stamp GW, Wolhuter K, Stevens M, Fischer R, Carmeliet P, Maxwell PH, Pugh CW, Frizzell N, Soga T, Kessler BM, El-Bahrawy M, Ratcliffe PJ, Pollard PJ (2011) Renal cyst formation in Fh1-deficient mice is independent of the Hif/Phd pathway: roles for fumarate in keap1 succination and Nrf2 signaling. Cancer Cell 20:524-537

192. Gozzelino R, Jeney V, Soares MP (2010) Mechanisms of cell protection by heme oxygenase-1. Annu Rev Pharmacol Toxicol 50:323-354

193. Deshane J, Chen S, Caballero S, Grochot-Przeczek A, Was H, Li Calzi S, Lach R, Hock TD, Chen B, Hill-Kapturczak N, Siegal GP, Dulak J, Jozkowicz A, Grant MB, Agarwal A (2007) Stromal cell-derived factor 1 promotes angiogenesis via a heme oxygenase 1-dependent mechanism. J Exp Med 204:605-618

194. Dulak J, Jozkowicz A, Foresti R, Kasza A, Frick M, Huk I, Green CJ, Pachinger O, Weidinger F, Motterlini R (2002) Heme oxygenase activity modulates vascular endothelial growth factor synthesis in vascular smooth muscle cells. Antioxid Redox Signal 4:229-240

195. Jozkowicz A, Huk I, Nigisch A, Weigel G, Dietrich W, Motterlini R, Dulak J (2003) Heme oxygenase and angiogenic activity of endothelial cells: stimulation by carbon monoxide and inhibition by tin protoporphyrin-ix. Antioxid Redox Signal 5:155-162

196. Was H, Dulak J, Jozkowicz A (2010) Heme oxygenase-1 in tumor biology and therapy. Curr Drug Targets 11:1551-1570

197. Marinissen MJ, Tanos T, Bolos M, de Sagarra MR, Coso OA, Cuadrado A (2006) Inhibition of heme oxygenase-1 interferes with the transforming activity of the Kaposi sarcoma herpesvirus-encoded $G$ protein-coupled receptor. J Biol Chem 281:11332-11346

198. Martin MJ, Tanos T, Garcia AB, Martin D, Gutkind JS, Coso OA, Marinissen MJ (2007) The Galpha12/13 family of heterotrimeric $g$ proteins and the small GTPase RhoA link the Kaposi sarcoma-associated herpes virus $G$ protein-coupled receptor to heme oxygenase- 1 expression and tumorigenesis. J Biol Chem 282:34510-34524

199. Mayerhofer M, Florian S, Krauth MT, Aichberger KJ, Bilban M, Marculescu R, Printz D, Fritsch G, Wagner O, Selzer E, Sperr WR, Valent P, Sillaber C (2004) Identification of heme oxygenase-1 as a novel BCR/ABL-dependent survival factor in chronic myeloid leukemia. Cancer Res 64:3148-3154

200. Banerjee P, Basu A, Arbiser JL, Pal S (2013) The natural product honokiol inhibits calcineurin inhibitor-induced and Ras-mediated tumor promoting pathways. Cancer Lett 338:292-299

201. Nagy P, Varga A, Pircs K, Hegedus K, Juhasz G (2013) Mycdriven overgrowth requires unfolded protein response-mediated induction of autophagy and antioxidant responses in Drosophila melanogaster. PLoS Genet 9:e1003664

202. Levy S, Forman HJ (2010) C-Myc is a Nrf2-interacting protein that negatively regulates phase II genes through their electrophile responsive elements. IUBMB Life 62:237-246

203. Loboda A, Stachurska A, Florczyk U, Rudnicka D, Jazwa A, Wegrzyn J, Kozakowska M, Stalinska K, Poellinger L, Levonen AL, Yla-Herttuala S, Jozkowicz A, Dulak J (2009) HIF-1 induction attenuates Nrf2-dependent IL-8 expression in human endothelial cells. Antioxid Redox Signal 11:1501-1517

204. Was H, Sokolowska M, Sierpniowska A, Dominik P, Skrzypek K, Lackowska B, Pratnicki A, Grochot-Przeczek A, Taha H, Kotlinowski J, Kozakowska M, Mazan A, Nowak W, Muchova L, Vitek L, Ratajska A, Dulak J, Jozkowicz A (2011) Effects of heme oxygenase- 1 on induction and development of chemically induced squamous cell carcinoma in mice. Free Radic Biol Med 51:1717-1726

205. Wakabayashi N, Itoh K, Wakabayashi J, Motohashi H, Noda S, Takahashi S, Imakado S, Kotsuji T, Otsuka F, Roop DR, Harada T, Engel JD, Yamamoto M (2003) Keap1-null mutation leads to postnatal lethality due to constitutive Nrf2 activation. Nat Genet $35: 238-245$

206. Narasimhan M, Rajasekaran NS (2015) Reductive potential-a savior turns stressor in protein aggregation cardiomyopathy. Biochim Biophys Acta 1852:53-60

207. Rajasekaran NS, Connell P, Christians ES, Yan LJ, Taylor RP, Orosz A, Zhang XQ, Stevenson TJ, Peshock RM, Leopold JA, Barry WH, Loscalzo J, Odelberg SJ, Benjamin IJ (2007) Human alpha B-crystallin mutation causes oxido-reductive stress and protein aggregation cardiomyopathy in mice. Cell 130:427-439

208. Zhang X, Min X, Li C, Benjamin IJ, Qian B, Zhang X, Ding Z, Gao X, Yao Y, Ma Y, Cheng Y, Liu L (2010) Involvement of reductive stress in the cardiomyopathy in transgenic mice with cardiac-specific overexpression of heat shock protein 27. Hypertension 55:1412-1417

209. Rajasekaran NS, Varadharaj S, Khanderao GD, Davidson CJ, Kannan S, Firpo MA, Zweier JL, Benjamin IJ (2011) Sustained activation of nuclear erythroid 2-related factor 2/antioxidant response element signaling promotes reductive stress in the human mutant protein aggregation cardiomyopathy in mice. Antioxid Redox Signal 14:957-971

210. Kannan S, Muthusamy VR, Whitehead KJ, Wang L, Gomes AV, Litwin SE, Kensler TW, Abel ED, Hoidal JR, Rajasekaran NS (2013) Nrf2 deficiency prevents reductive stress-induced hypertrophic cardiomyopathy. Cardiovasc Res 100:63-73

211. Chorley BN, Campbell MR, Wang X, Karaca M, Sambandan D, Bangura F, Xue P, Pi J, Kleeberger SR, Bell DA (2012) Identification of novel NRF2-regulated genes by ChIP-Seq: influence on retinoid x receptor alpha. Nucleic Acids Res 40:7416-7429

212. Eades G, Yang M, Yao Y, Zhang Y, Zhou Q (2011) mirR-200a regulates Nrf2 activation by targeting Keap1 mRNA in breast cancer cells. J Biol Chem 286:40725-40733

213. Yang M, Yao Y, Eades G, Zhang Y, Zhou Q (2011) Mir-28 regulates Nrf2 expression through a Keap1-independent mechanism. Breast Cancer Res Treat 129:983-991

214. Sangokoya C, Telen MJ, Chi JT (2010) microRNA mir-144 modulates oxidative stress tolerance and associates with anemia severity in sickle cell disease. Blood 116:4338-4348 
215. Singh A, Happel C, Manna SK, Acquaah-Mensah G, Carrerero J, Kumar S, Nasipuri P, Krausz KW, Wakabayashi N, Dewi R, Boros LG, Gonzalez FJ, Gabrielson E, Wong KK, Girnun G, Biswal S (2013) Transcription factor nrf2 regulates mir-1 and mir-206 to drive tumorigenesis. J Clin Invest 123:2921-2934

216. Kozakowska M, Ciesla M, Stefanska A, Skrzypek K, Was H, Jazwa A, Grochot-Przeczek A, Kotlinowski J, Szymula A, Bartelik A, Mazan M, Yagensky O, Florczyk U, Lemke K, Zebzda A, Dyduch G, Nowak W, Szade K, Stepniewski J, Majka M, Derlacz R, Loboda A, Dulak J, Jozkowicz A (2012) Heme oxygenase-1 inhibits myoblast differentiation by targeting myomirs. Antioxid Redox Signal 16:113-127

217. Skrzypek K, Tertil M, Golda S, Ciesla M, Weglarczyk K, Collet G, Guichard A, Kozakowska M, Boczkowski J, Was H, Gil T,
Kuzdzal J, Muchova L, Vitek L, Loboda A, Jozkowicz A, Kieda C, Dulak J (2013) Interplay between heme oxygenase-1 and mir378 affects non-small cell lung carcinoma growth, vascularization, and metastasis. Antioxid Redox Signal 19:644-660

218. Tertil M, Golda S, Skrzypek K, Florczyk U, Weglarczyk K, Kotlinowski J, Maleszewska M, Czauderna S, Pichon C, Kieda C, Jozkowicz A, Dulak J (2015) Nrf2-heme oxygenase-1 axis in mucoepidermoid carcinoma of the lung: antitumoral effects associated with down-regulation of matrix metalloproteinases. Free Radic Biol Med 89:147-157

219. Lin SH, Song W, Cressatti M, Zukor H, Wang E, Schipper HM (2015) Heme oxygenase-1 modulates microRNA expression in cultured astroglia: implications for chronic brain disorders. Glia 63:1270-1284 